\title{
THE ROTTERDAM DEMAND MODEL HALF A CENTURY ON*
}

\author{
by \\ Kenneth W Clements \\ Business School \\ The University of Western Australia \\ and \\ Grace Gao \\ Bankwest Curtin Economics Centre \\ Curtin University
}

\begin{abstract}
The system-wide approach to demand analysis emphasises the interrelatedness of all $n$ elements of the consumption basket and leads to a set of demand equations characterised by $n$ income elasticities and an $n \times n$ matrix of own and cross-price elasticities. This approach is now used on a routine basis in CGE modelling, the measurement of the deadweight loss of distortions in consumption and a number of other areas in applied economics. Half a century ago, Barten (1964) and Theil (1965) formulated what is now known as the Rotterdam model, which is now an important member of the system-wide family. A path-breaking innovation, this model allowed for the first time rigorous testing of the theory of the utility-maximising consumer. This has led to a vibrant, on-going strand of research on the theoretical underpinnings of the model, extensions and numerous applications. But perhaps due to its European heritage and unorthodox derivation, there is still misunderstanding and a tendency for the Rotterdam model to be regarded with reservations and/or uncertainties (if not mistrust). This paper marks the golden jubilee of the model by clarifying its foundations, highlighting its strengths and weaknesses, elucidating its links with other models of consumer demand, and dealing with some recent developments that have their roots in Barten and Theil's pioneering research of the 1960s.
\end{abstract}

Corresponding author: Kenneth W Clements, telephone +61-08-64882898 ken.clements@uwa.edu.au

\section{Highlights}

- Comprehensive review of the Rotterdam model.

- Detailed account of the economic foundations, strengths and weaknesses of model.

- Little-known close links with other popular demand models are highlighted.

- The Rotterdam is likely to continue to play a prominent (and controversial?) role.

\footnotetext{
* For encouragement and helpful suggestions, we would like to thank Bert Balk, William Barnett, Erwin Diewert, Denzil Fiebig, Paul Frijters, Essie Maasoumi, Ranjan Ray, George Verikios, Antony Selvanathan, Thomas Simpson, Wana Yang, the Editor and two anonymous referees of this journal, and seminar participants at UWA. We are also grateful to Aiden Depiazzi, Haiyan Liu and Jiawei Si for excellent research assistance. This research was financed in part by the ARC and BHP Billiton.
} 


\section{INTRODUCTION}

Few papers in economics have a working life, in terms of citations and influence, longer than a decade or so. It is thus a very rare event for a paper to continue to be read, cited, taught and followed after half a century. Two such papers are Anton Barton’s “Consumer Demand Equations Under Conditions of Almost Additive Preferences” and Henri Theil’s “The Information Approach to Demand Analysis” that were published in Econometrica in 1964 and 1965, respectively (Barten, 1964, Theil, 1965). Those related papers introduced what has become known as the "Rotterdam model”. For the first time, this model combined generality and operational tractability so that it became a prominent vehicle for the econometric analysis of the pattern of consumer demand and the rigorous testing of utility-maximisation theory. To this day, the model still appears in leading journals, and the general approach has formed the basis for a rich class of models known as the “differential approach" to demand analysis that is used in both time-series and cross-country applications. The Rotterdam model has spawned a rich and extensive literature and occupies a similar status in consumer demand to the linear expenditure system (LES, Stone, 1954), the translog (Christensen et al., 1975) and the almost ideal demand system (Deaton and Muelbauer, 1980a). Figure 1 provides some evidence for this claim in terms of citations.

The beguiling simplicity, transparency and apparent generality of the Rotterdam model have led to its prominent position in demand analysis. Interestingly (ironically?), these very features have led to controversy, misunderstanding and a feeling that perhaps the Rotterdam system was "too good to be true” and its simplicity deceptive. Non-Rotterdam approaches such as the LES start with the algebraic form of the consumer's utility function and then derive the corresponding demand functions, which obviously contain (most of) the information embodied in the utility function. This sequence is reversed in the Rotterdam approach. It starts with demand functions, takes the total differential, uses utility-maximising theory to give restrictions on the demand functions and then, as the last step, takes certain transformations of the slopes of the demand functions to be constants. The important distinction is that the utility function is not specified explicitly, but lies behind the demand equations in the background. Preferences are not ignored as the utility function provides restrictions on (transforms of) the slopes of the demand equations. In this sense, the Rotterdam system can be considered to be consistent with a variety of utility functions.

As the underlying theory can confront the data only via demand functions, there is the merit of directness in the Rotterdam approach. Expressing the consumer's preferences in the form of the utility function or the cost function involves a construct that is unobservable; in this sense, competitive approaches that start by specifying preferences are indirect in the theory-data matching 
process. A related issue is the question of parameterisation of the Rotterdam, which contains a mixture of slopes of Engel functions and a type of semi-elasticity for the prices. This formulation is unconventional and has been the source of some difficulties and resistance. For the non-Rotterdam approaches the question of parameterisation is simple: Choose the algebraic form of the utility function (direct or indirect) or the cost function, which then determines the form of the demand equations. The reverse engineering methodology makes the Rotterdam appear different and distinct and, arguably, is at the heart of the controversy and misunderstanding. Rotterdam critics also argue the microeconomic foundations of the model are questionable and have claimed it implies CobbDouglas preferences, so that all income elasticities are unity and price elasticities are -1 , which, if true, would be a devastating weakness.

Why does the Rotterdam model continue to be used after so long and endure in view of such apparent trenchant criticism? Some of the controversy will possibly never be completely settled, and, of course, it is not productive to be dogmatic in matters that are inherently unresolvable if they simply reflect different preferences (of researchers). The fact is the Rotterdam passes the Darwinian test of survival by a sizable margin, and it seems it will continue to be used for some time in the future. It is thus appropriate to mark the first half century of the Rotterdam model's existence with a review that sets out the model, its advantages and disadvantages with the objective of clarifying at least some of the misunderstanding that still surrounds the model. It is also appropriate to provide a unified account of the developments that the Rotterdam directly lead to - the differential approach and the emerging area of cross-county demand analysis. This material reveals surprisingly close links between the Rotterdam and other popular models.

\section{THE ORIGINAL FORMULATION}

This section presents a selective overview of the model due to Barten (1964) and Theil (1965). ${ }^{1}$ Let $p_{i}$ and $q_{i}$ be the price and quantity demanded of good $i, i=1, \ldots, n$. The consumer is taken to choose the basket $\mathrm{q}_{1}, \ldots, \mathrm{q}_{\mathrm{n}}$ to maximise the utility function

$$
\mathrm{u}\left(\mathrm{q}_{1}, \ldots, \mathrm{q}_{\mathrm{n}}\right)
$$

\footnotetext{
${ }^{1}$ Two additional "basic sources" for the Rotterdam model are Theil (1967, Chap 5-6) and Theil (1975/76). For reviews of the broader area of applied demand analysis, see Barnett and Serletis (2008), Barten (1977), Bewley (1986). Blundell (1988), Brown and Deaton (1972), Deaton (1986), Deaton and Muelbauer (1980b), Goldberger (1987), Phlips (1974), Pollak and Wales (1992), Powell (1974), Theil (1980) and Theil and Clements (1987). The topic of demand systems is a prominent area in economic modelling/applied econometrics: Some examples of recent papers on demand systems from this journal are Cranfield and Pellow (2004), Cranfield et al. (2004), Duffy (2002), Filippini et al. (2009), Li et al. (2015), Lyons et al. (2009), Tridimas (2000) and Yu et al. (2003).
} 
subject to the budget constraint $M=\sum_{i=1}^{n} p_{i} q_{i}$, where $M$ is total expenditure ("income” for short). This leads to a demand equation for good $i$ of the form $q_{i}=q_{i}\left(M, p_{1}, \ldots, p_{n}\right)$. As money income is held constant, this is a Marshallian demand equation. The differential of this demand equation is

$$
\mathrm{dq}_{\mathrm{i}}=\frac{\partial \mathrm{q}_{\mathrm{i}}}{\partial \mathrm{M}} \mathrm{dM}+\sum_{\mathrm{j}=1}^{\mathrm{n}} \frac{\partial \mathrm{q}_{\mathrm{i}}}{\partial \mathrm{p}_{\mathrm{j}}} \mathrm{dp}_{\mathrm{j}}
$$

The total effect on the consumption of good $i$ of a change in the price of good $j, \partial q_{i} / \partial p_{j}$, can be decomposed into the income and substitution effects according to the Slutsky equation, $\partial \mathrm{q}_{\mathrm{i}} / \partial \mathrm{p}_{\mathrm{j}}=\mathrm{s}_{\mathrm{ij}}-\mathrm{q}_{\mathrm{j}} \partial \mathrm{q}_{\mathrm{i}} / \partial \mathrm{M}$, where $\mathrm{s}_{\mathrm{ij}}$ is the substitution effect that holds real income constant. Thus, the above can be expressed as

$$
\mathrm{dq}_{\mathrm{i}}=\frac{\partial \mathrm{q}_{\mathrm{i}}}{\partial \mathrm{M}}\left(\mathrm{dM}-\sum_{\mathrm{j}=1}^{\mathrm{n}} \mathrm{q}_{\mathrm{j}} \mathrm{dp} \mathrm{p}_{\mathrm{j}}\right)+\sum_{\mathrm{j}=1}^{\mathrm{n}} \mathrm{s}_{\mathrm{ij}} \mathrm{dp} \mathrm{p}_{\mathrm{j}}
$$

The term in brackets is the change in money income deflated by the income effects of the $\mathrm{n}$ price changes, which represents the change in real income. Multiplying both sides by $1 / q_{i}$ and using the identity $d(\log x)=d x / x$, the above can be expressed logarithmically as

$$
d\left(\log q_{i}\right)=\frac{M}{q_{i}} \frac{\partial q_{i}}{\partial M}\left[d(\log M)-\sum_{j=1}^{n} \frac{p_{j} q_{j}}{M} d\left(\log p_{j}\right)\right]+\sum_{j=1}^{n} \frac{p_{j}}{q_{i}} s_{i j} d\left(\log p_{j}\right) .
$$

Define $\mathrm{w}_{\mathrm{i}}=\mathrm{p}_{\mathrm{i}} \mathrm{q}_{\mathrm{i}} / \mathrm{M}$ as the budget share of good $\mathrm{i}$ and Divisia (1925) indexes of (the change in) real income and prices,

$$
\mathrm{d}(\log \mathrm{Q})=\sum_{\mathrm{i}=1}^{\mathrm{n}} \mathrm{w}_{\mathrm{i}} \mathrm{d}\left(\log \mathrm{q}_{\mathrm{i}}\right) \text { and } \mathrm{d}(\log \mathrm{P})=\sum_{\mathrm{i}=1}^{\mathrm{n}} \mathrm{w}_{\mathrm{i}} \mathrm{d}\left(\log \mathrm{p}_{\mathrm{i}}\right) \text {. }
$$

Using $d(\log M)=d(\log P)+d(\log Q)$, which follows from the budget constraint, equation (2.2) can be simplified to

$$
d\left(\log q_{i}\right)=\eta_{i} d(\log Q)+\sum_{j=1}^{n} \eta_{i j} d\left(\log p_{j}\right),
$$

where $\eta_{i}=\partial\left(\log q_{i}\right) / \partial(\log M)$ is the income elasticity of good $i$ and $\eta_{i j}=\left(p_{j} / q_{i}\right) s_{i j}$ is the $(i, j)^{\text {th }}$ price elasticity (income compensated). For $\mathrm{i}=1, \ldots, \mathrm{n},(2.3)$ is a system of $\mathrm{n}$ demand equations, the parameters of which satisfy the adding-up constraints implied the budget constraint

$$
\sum_{i=1}^{n} w_{i} \eta_{i}=1, \quad \sum_{i=1}^{n} w_{i} \eta_{i j}=0, \quad j=1, \ldots, n .
$$

As real income is controlled for in equation (2.3), demand homogeneity means that an equiproportional increase in all prices has no effect on quantities consumed, which implies 


$$
\sum_{j=1}^{n} \eta_{i j}=0, i=1, \ldots, n
$$

Slutsky symmetry states that the substitution effects are symmetric in $\mathrm{i}$ and $\mathrm{j}$, that is, $\mathrm{s}_{\mathrm{ij}}=\mathrm{s}_{\mathrm{ji}}$, or

$w_{i} \eta_{i j}=w_{j} \eta_{j i}, i, j=1, \ldots, n$.

To apply model (2.3) to time-series data, Barten (1964) replaces infinitesimal changes with finite changes and takes the elasticities to be constants:

$$
\mathrm{Dq}_{\mathrm{it}}=\eta_{\mathrm{i}} \mathrm{DQ}_{\mathrm{t}}+\sum_{\mathrm{j}=1}^{\mathrm{n}} \eta_{\mathrm{ij}} \mathrm{Dp}_{\mathrm{jt}}+\varepsilon_{\mathrm{it}}, \quad \mathrm{i}=1, \ldots, \mathrm{n} \text { goods and } \mathrm{t}=1, \ldots, \mathrm{T} \text { observations, }
$$

where $\mathrm{D}$ denotes the log-change operator $\left(\mathrm{Dx} \mathrm{t}_{\mathrm{t}}=\log \mathrm{x}_{\mathrm{t}}-\log \mathrm{x}_{\mathrm{t}-1}\right)$ and $\varepsilon_{\mathrm{it}}$ is a disturbance term. This is an n-equation system that is linear in the parameters, the elasticities. Furthermore, the homogeneity constraint (2.5) is also linear. These are attractive features of the model, and Barten (1964, p. 8) justifies its use "for reasons that are largely pragmatic". Not so attractive is the appearance of the budget shares in constraints (2.4) and (2.6). Barten (1964) treats the shares as constants in these constraints and replaces them with their sample means.

Theil (1965) deals with the difficulty of the shares in the constraints by multiplying both sides of (2.3) by the budget share and then reparameterising:

$$
w_{i} d\left(\log q_{i}\right)=\theta_{i} d(\log Q)+\sum_{j=1}^{n} \pi_{i j} d\left(\log p_{j}\right),
$$

where $\theta_{\mathrm{i}}=\mathrm{w}_{\mathrm{i}} \eta_{\mathrm{i}}$ and $\pi_{\mathrm{ij}}=\mathrm{w}_{\mathrm{i}} \eta_{\mathrm{ij}}$. The parameter $\theta_{\mathrm{i}}=\partial\left(\mathrm{p}_{\mathrm{i}} \mathrm{q}_{\mathrm{i}}\right) / \partial \mathrm{M}$ is known as the marginal share of good i. As any increase in income is taken to be completely spent, the marginal shares have a unit sum:

(2.9) $\quad \sum_{i=1}^{n} \theta_{i}=1$.

The coefficient $\pi_{\mathrm{ij}}$ refers to the substitution effect of a change in the price of good $\mathrm{j}$ on the demand for good $\mathrm{i}$ when real income is held constant and is known as the $(\mathrm{i}, \mathrm{j})^{\text {th }}$ Slutsky coefficient. As $\eta_{\mathrm{ij}}=\pi_{\mathrm{ij}} / \mathrm{w}_{\mathrm{i}}$, the homogeneity constraint (2.5) and symmetry constraints (2.6) becomes

(2.10) $\sum_{\mathrm{j}=1}^{\mathrm{n}} \pi_{\mathrm{ij}}=0$ and $\pi_{\mathrm{ij}}=\pi_{\mathrm{ji}}, \quad \mathrm{i}, \mathrm{j}=1, \ldots, \mathrm{n}$.

It can be seen that all three constraints now are satisfied as parametric restrictions without any reference to the (variable) budget shares. This constitutes a brilliantly simple resolution to the problem. 
For changes over time from period t-1 to t, the budget share in equation (2.8) in either of these two periods would seem to have equal merits. But to choose one leads to an asymmetry that is best avoided. To treat both periods symmetrically, Theil (1965) proposes a two-period moving average of the share over $t-1, t, \bar{w}_{i t}=\left(w_{i, t-1}+w_{i t}\right) / 2$, so the finite-change version of (2.8) is

$$
\overline{\mathrm{w}}_{\mathrm{it}} \mathrm{Dq}_{\mathrm{it}}=\theta_{\mathrm{i}} \mathrm{DQ} \mathrm{Q}_{\mathrm{t}}+\sum_{\mathrm{j}=1}^{\mathrm{n}} \pi_{\mathrm{ij}} \mathrm{Dp} \mathrm{p}_{\mathrm{jt}}+\mu_{\mathrm{it}}, \quad \mathrm{i}=1, \ldots, \mathrm{n} \text { goods and } \mathrm{t}=1, \ldots, \mathrm{T} \text { observations, }
$$

with $\theta_{\mathrm{i}}=\overline{\mathrm{w}}_{\mathrm{it}} \eta_{\mathrm{i}}$ and $\pi_{\mathrm{ij}}=\overline{\mathrm{w}}_{\mathrm{it}} \eta_{\mathrm{ij}}$, which are taken to be constants, and $\mu_{\mathrm{it}}=\overline{\mathrm{w}}_{\mathrm{it}} \varepsilon_{\mathrm{it}}$ is the new disturbance. Thus, we move from a constant elasticity formulation (2.7) to (2.11), which is known as the Rotterdam model $^{2}{ }^{2}$ It describes the budget-share weighted change in the quantity consumed of good $\mathrm{i}, \overline{\mathrm{w}}_{\mathrm{it}} \mathrm{Dq} \mathrm{q}_{\mathrm{it}}$, as a linear function of the change in real income and the change in each of the $\mathrm{n}$ prices. The income variable is $\mathrm{DQ}_{\mathrm{t}}=\sum_{\mathrm{i}=1}^{\mathrm{n}} \overline{\mathrm{w}}_{\mathrm{it}} \mathrm{Dq}_{\mathrm{it}}$, which is a frequently employed discrete approximation of the Divisia volume index. ${ }^{3}$ As model (2.11) is linear in the parameters, when income and the prices are taken as exogenous it can be estimated as a seemingly unrelated regression system. Moreover, as the homogeneity and symmetry constraints are also linear, their testing would also seem to be straightforward. But as Laitinen (1978) and Meisner (1979) showed with Monte Carlo studies, the conventional tests based on asymptotic theory breakdown when the number of goods $\mathrm{n}$ is large relative to the number of time periods. These tests can be modified appropriately, however. $^{4}$

\section{CRITICISMS}

Like all models, the Rotterdam system can at best be considered as only an approximation to reality and not perfect. In this section we consider three criticisms of the model.

(i) Constant Marginal Shares. The marginal share, $\theta_{i}$, is constant in equation (2.11). This implies that the income elasticity is inversely proportional to the corresponding budget share. To

\footnotetext{
2 The name, due to Parks (1969), reflects the location of Barten and Theil when the model was first formulated. Theil moved from The Netherlands School of Economics (now Erasmus University Rotterdam) to The University of Chicago in 1966, then in 1981 to The University of Florida, Gainesville and retired in 1994. He died in 2000. Barten, Theil's former student, moved from Rotterdam to The Catholic University of Louvain and then later to Tilburg University. For biographical information on these two pioneers of econometrics, see Barnett (2003), Bewley (2000), Blaug (1999), Clements (2001), Kloek (2001), Koerts (1992), Raj (1992) and Seale and Moss (2003).

${ }^{3}$ Defining real income as the sum of the left-hand variables means that model (2.11) is an allocation system. That is, given the price changes and the values of the disturbances, the $n$ equations of the model allocate income to each of the $n$ goods. Knowledge of $n-1$ allocations is sufficient to determine that of the $n^{\text {th }}$; in other words, the Rotterdam model is a singular system in which one equation is redundant. This means that the model satisfies the budget constraint. That is, the adding-up constraints are automatically satisfied and not testable.

${ }^{4}$ For an account of these and related matters, see Theil (1987).
} 
understand the implications, it is convenient to use infinitesimal changes. When prices are held constant, it follows from $\mathrm{w}_{\mathrm{i}}=\mathrm{p}_{\mathrm{i}} \mathrm{q}_{\mathrm{i}} / \mathrm{M}$ that

$$
d\left(\log w_{i}\right)=d\left(\log q_{i}\right)-d(\log M)=\left(\eta_{i}-1\right) d(\log M) .
$$

where $\eta_{i}$ is the income elasticity of good i. As $\eta_{i}=\theta_{i} / w_{i}$, the constant marginal share means $\mathrm{d}\left(\log \eta_{\mathrm{i}}\right)=-\mathrm{d}\left(\log \mathrm{w}_{\mathrm{i}}\right)$, so that

$$
d\left(\log \eta_{i}\right)=-\left(\eta_{i}-1\right) d(\log M) .
$$

This shows that the income elasticity of the income elasticity is $-\left(\eta_{i}-1\right)$. Accordingly, for luxuries $\left(\eta_{i}>1\right)$, income growth causes the income elasticity to fall, while the reverse is true for necessities. This type of behaviour is problematic for food, the leading necessity, as it means that its income elasticity for the rich is larger than that for the poor: Food is less of a necessity, or more of a luxury, for a more affluent consumer! This makes no economic sense and is contradicted by several studies. ${ }^{5}$

A simple rectification is possible by using Working's (1943) model whereby the budget share is a linear function of the logarithm of income:

$$
\mathrm{w}_{\mathrm{i}}=\alpha_{\mathrm{i}}+\beta_{\mathrm{i}} \log \mathrm{M} \text {, }
$$

where $\alpha_{i}$ and $\beta_{i}$ are parameters. ${ }^{6}$ The implied marginal share is $\theta_{i}=w_{i}+\beta_{i}$. Rather than being a constant itself, now the marginal share differs from the corresponding budget share by a constant, $\beta_{\mathrm{i}}$. The income elasticity is

$$
\eta_{\mathrm{i}}=1+\frac{\beta_{\mathrm{i}}}{\mathrm{w}_{\mathrm{i}}}
$$

so that the good is a luxury (necessity) if its $\beta_{\mathrm{i}}>0(<0)$. The differential of (3.2) can be expressed as $d\left(\log \eta_{i}\right)=-\left[\left(\eta_{i}-1\right) / \eta_{i}\right] d\left(\log w_{i}\right)$, so that

$$
d\left(\log \eta_{i}\right)=-\left[\frac{\left(\eta_{i}-1\right)^{2}}{\eta_{i}}\right] d(\log M) .
$$

Now, the income elasticity always falls as income grows (as long as $\eta_{i}>0$ ): The food income elasticity for the rich is now lower than that for the poor, which solves the previous problem.

\footnotetext{
${ }^{5}$ See, e. g., Clements and S. Selvanathan (1994), Deaton and Paxson (1998), Gao (2012), Hymans and Shapiro (1976), Lluch et al. (1977) and Timmer and Alderman (1979).

${ }^{6}$ This model is also associated with Leser (1963). For economy of notation, here and elsewhere the same symbols are used to denote different parameters. This will cause no confusion as the meaning is clear from the context.
} 
(ii) Constant Slutsky Coefficients. The Slutsky coefficients are defined as

$$
\pi_{i j}=\frac{p_{i} p_{j}}{M} \cdot s_{i j} \text {, with } s_{i j}=\left.\frac{\partial q_{i}}{\partial p_{j}}\right|_{D Q=0} \text {, for } i, j=1, \ldots, n \text {. }
$$

The Slutsky coefficient $\pi_{\mathrm{ij}}$ involves prices, income and preferences to give the response to the $\mathrm{j}^{\text {th }}$ price when the consumer remains on the same indifference curve. An objection is that this mixture of the subjective (preferences) and the objective (prices and income) is somehow mixed up. This objection has been heard (but apparently not written down) at The University of Chicago and possibly reflects the influence of Milton Friedman that preferences are distinct from the budget constraint and those who mix the two do so at their peril. While this is no doubt a good guiding principle of applied price theory, the objection has little merit in the context of the Rotterdam model that is used for something else, applied demand analysis.

Clearly, the $\pi_{\mathrm{ij}}$ cannot be constants if one insists on constant derivatives. It may be common practice to think of derivatives as being more or less constant, but this is just a matter of convenience as there is no fundamental reason for these derivatives to be constants. More generally, the selection between demand models actually involves the question of what is constant and what is variable. For example, if $\pi_{\mathrm{ij}}$ is constant as in the Rotterdam model (2.11), the price elasticity $\eta_{\mathrm{ij}}$ varies with $\mathrm{w}_{\mathrm{i}}$, and vice versa in the double-log model (2.7). Furthermore, as the price elasticity is $\eta_{\mathrm{ij}}=\pi_{\mathrm{ij}} / \mathrm{w}_{\mathrm{i}}$, $\mathrm{d}\left(\log \eta_{\mathrm{ij}}\right)=-\mathrm{d}\left(\log \mathrm{w}_{\mathrm{i}}\right)$ when $\pi_{\mathrm{ij}}$ is constant; like the income elasticity, the price elasticity is inversely proportional to the budget share. If income grows, the budget shares of necessities fall, so that the price elasticities of these goods all increase; and vice versa for luxuries. In some situations, this may be an unpalatable consequence of the Rotterdam parameterisation.

(iii) Degenerate Preferences. Since the Rotterdam model is formulated in terms of changes over time, what are the implications of the model for the demand equations in terms of levels, $\mathrm{q}_{\mathrm{i}}=\mathrm{q}_{\mathrm{i}}\left(\mathrm{M}, \mathrm{p}_{1}, \ldots, \mathrm{p}_{\mathrm{n}}\right)$, for $\mathrm{i}=1, \ldots, \mathrm{n}$ ? McFadden (1964) showed that the implications are rather drastic: The Rotterdam is only consistent with a levels demand equation for all values of income and prices when $q_{i}=\alpha_{i}\left(M / p_{i}\right)$, where $\alpha_{i}$ is a constant. This means that each budget share is constant, $\mathrm{p}_{\mathrm{i}} \mathrm{q}_{\mathrm{i}} / \mathrm{M}=\alpha_{\mathrm{i}}$, so that all income elasticites are equal to 1 , own-price elasticites -1 and cross-price elasticities 0. As these features violate Engel's law, economic intuition, and are not observed in practice, the McFadden critique would seem to greatly diminish the usefulness of the Rotterdam model. 
There have been two main responses to this criticism. The first is the pragmatic approach to regard all models as approximations that hold over some limited range of data only, rather than globally. Thus, Theil (1967, p. 203) writes:

[The] constancy [of the coefficients of the Rotterdam model (2.11)] is restrictive, of course. It implies, as far as $\left[\theta_{i}=\partial\left(p_{i} q_{i}\right) / \partial M\right]$ is concerned, that the optimal quantities are linear functions of income. Although this is probably not too serious when real income and relative prices are subject to moderate changes, it should be realised that equation [(2.11)] -- or, for that matter, any other form of demand equation -- is a Procrustean bed which fits empirical observations imperfectly. The main justification of [(2.11)] is it simplicity... Since our starting point was formulated in terms of first-order effects (infinitesimal changes), the implications of the demand equations should also be confined to first-order changes.

This approach to applied work is also exemplified in Theil's (1971, p. vi) declaration that “models are to be used but not to be believed". ${ }^{7}$ Goldberger (1987, p. 96) expresses the issue slightly differently:

If one is to assess the fruitfulness of the Rotterdam [model], it is important to recognise that no stigma attaches to [its] being approximate rather than exact. With the true utility function being unknown, there is after all no guarantee that any of the "exact" consumer demand models will be exact in fact. [The Rotterdam model], quite possibly, provides an adequate approximation to utility-maximising behaviour over a range of conceivable true utility functions; this without being exactly appropriate for any particular one. Such robustness is naturally attractive.

A second response to the McFadden critique is to realise that strictly speaking, the economic theory of the consumer, which gives rise to the homogeneity and symmetry constraints, applies to the individual consumer only. Thus, we might start with micro demand equations for each individual and then inquire about the nature of the aggregated, or macro, demand equations. Barnett (1979b), Theil (1971, 1975/76) and E. A. Selvanathan (1991) use the convergence approach (or random coefficients) to aggregate micro-level differential demand equations. Under not unreasonable conditions, the Rotterdam model emerges from this analysis as a Taylor-series approximation to the aggregated demand equations. This response would seem to reinforce the approach of treating models as approximating reality, not mirroring it. $^{8}$

A related misunderstanding of the Rotterdam model comes from the unfamiliar way in which the model is derived. Most other demand systems are derived from an algebraic specification of the utility or cost function, so the parameters (or some transforms thereof) are from the underlying

\footnotetext{
${ }^{7}$ But note that this statement comes with a qualifier in the full sentence: "It does require maturity to realise that models are to be used but not to be believed.” Those who struggle with this rule may be suffering from immaturity!

${ }^{8}$ For further research on the Rotterdam model as an approximation, see Barnett (1984), Byron (1984) and Mountain (1988).
} 
objective function. The derivation of the Rotterdam model follows a different path that involves a three-step process:

1. Start with a general system of differential demand equations.

2. Constrain these equations so that they satisfy homogeneity and symmetry. These constraints come out of the solution to the budget-constrained utility maximisation problem, but the specific functional form is unspecified. As at this stage, the "coefficients" of the demand equation are not constant, the approach is general and consistent with any algebraic form of the utility or cost function. This generality will be illustrated in the next section by presenting other popular demand models in differential format.

3. Finally, infinitesimal changes are replaced with finite changes and the model is parameterised by taking the marginal shares and Slutsky coefficients to be constants.

While it can take some mental "gear changing" to fully appreciate the workings of this approach, the logic is compelling and the three steps clarify the underpinnings of the model. Accordingly, while the coefficients in the Rotterdam equations do not come directly from the utility function, they have clear economic meaning. This approach opens up the possibility of generalisations by making the "parameters" functions of income and prices based on new hypotheses and/or intuitive considerations. Compared to the approach of specifying the utility function at the beginning, leaving parameterisation to the last step has the advantage that alternative functional forms can be easily investigated. ${ }^{9}$

\section{THE DIFFERENTIAL APPROACH}

Partly in response to the above criticisms, Theil (1980) introduced a more general formulation that represents a new class of model, or perhaps a new "mode" of analysis - the

\footnotetext{
9 Reviews of Theil's (1975/76) two-volume book give an appreciation of some of the less-than-enthusiastic critical reaction to the Rotterdam model. Muellbauer (1978) writes “original, idiosyncratic, highly specialised, massive are some of the terms brought to mind by the 850 pages in these two volumes". He goes on to acknowledge the overall quality of the work even if he is not completely enamoured with the approach. He concludes with a restrained summary evaluation that "[the books] represent coherent theorising and econometrics taken to their furthest limits in a narrowly defined area and will appeal to researchers in this area rather than to economists in general”. A second review by Horowitz (1978) is even harsher: "I found both books to be tedious reading that I wouldn't recommend to my worst enemy, and certainly not to the readership of Interfaces. On the other hand, neither I, my worst enemy, nor the overwhelming majority of our readership are intensely interested in the theory and measurement of consumer demand.” After expressing some grudging admiration ("an absolute must for scholars with a compulsion to turn their talents towards the estimation of consumer demand”), Horowitz states “[v]olume 1 contains an awful lot of mathematical manipulation, little of which is motivated, none of which is especially difficult or interesting, and almost all of which is presented in a cut-and-dried fashion that makes virtually no attempt to lure the reader into subsequent sections." The terms "idiosyncratic", "highly specialised”, "tedious", uninteresting "mathematical manipulation" can be interpreted as reflecting uncertainty, possible reservations and/or unfamiliarity with the Rotterdam model and the way in which it is derived. For another lukewarm/uncertain attitude to the Rotterdam approach, see Zhao (2008).
} 
differential approach. This section discusses the essentials of the approach. ${ }^{10}$ For convenience, we repeat the corresponding infinitesimal version of Rotterdam model (2.8),

$$
\mathrm{w}_{\mathrm{i}} \mathrm{d}\left(\log \mathrm{q}_{\mathrm{i}}\right)=\theta_{\mathrm{i}} \mathrm{d}(\log \mathrm{Q})+\sum_{\mathrm{j}=1}^{\mathrm{n}} \pi_{\mathrm{ij}} \mathrm{d}\left(\log \mathrm{p}_{\mathrm{j}}\right)
$$

In Section 2 the total effect of a price change was split into income and substitution effects. Barten (1964) went further to split the substitution effect into two distinct components, a "specific" effect and a "general" effect. The specific effect measures the degree of interactions between goods i and $\mathrm{j}$ in the utility function, while the general effect comes from the workings of the budget constraint and reflects the competition of all goods for the consumer's dollar. This was a breakthrough in consumer demand analysis as it provided for the first time a practical way to test for the degree of utility interactions, or separability. Barten (1964) showed that the substitution effect of a change in the price of good $\mathrm{j}$ and the demand for good $\mathrm{i}$ can be expressed as

$$
s_{i j}=\lambda u^{i j}-\frac{\lambda}{\partial \lambda / \partial M} \frac{\partial q_{i}}{\partial M} \frac{\partial q_{j}}{\partial M}
$$

Here, $\lambda$ is the marginal utility of income and $u^{i j}$ is the $(i, j)^{\text {th }}$ element of the inverse of the $n \times n$ Hessian matrix of the utility function, that is, $u^{i j}=\left[\partial^{2} u / \partial q_{i} \partial q_{j}\right]^{-1}$. The elements of this matrix describe how the marginal utility of each good changes as consumption of all others vary.

To illustrate the workings of equation (4.2), consider, for example, the demand for broad aggregates such as food, clothing, housing, etc. As there are likely to be only limited possibilities to substitute one of these goods for another, it might be reasonable to suppose there are no utility interactions. In such a case, utility is additive in each of the goods, $u\left(q_{1}, \ldots, q_{n}\right)=\sum_{i=1}^{n} u_{i}\left(q_{i}\right)$, where $\mathrm{u}_{\mathrm{i}}(\cdot)$ is the $\mathrm{i}^{\text {th }}$ sub-utility function that depends only on consumption of good $\mathrm{i}$. Thus, each marginal utility in independent of the consumption of all other goods, the Hessian is diagonal and so it its inverse. This implies that for each pair of goods $i \neq j$, $u^{i j}=0$, so that the first term on the right-hand side of equation (4.2) vanishes. This case is known as preference independence. Because $\mathrm{u}^{\mathrm{ij}}$ measures the interactions of the goods in utility and as this term cannot be decomposed into separate parts involving $\mathrm{i}$ and $\mathrm{j}, \lambda \mathrm{u}^{\mathrm{ij}}$ is called the specific substitution effect (Houthakker, 1960), and is symmetric in $\mathrm{i}$ and $\mathrm{j}$. The second term in equation (4.2), $-(\lambda / \partial \lambda / \partial \mathrm{M})\left(\partial \mathrm{q}_{\mathrm{i}} / \partial \mathrm{M}\right)\left(\partial \mathrm{q}_{\mathrm{j}} / \partial \mathrm{M}\right)$, is always present regardless of the nature of the utility function. This term is proportional to the product of the income slopes of the demand functions for the two goods in question, and thus can be decomposed.

\footnotetext{
${ }^{10}$ Barnett and Serletis (2009) study the differential approach in the context of the Rotterdam model.
} 
This second term is the general substitution effect (Houthakker, 1960), which is clearly symmetric in $\mathrm{i}$ and $\mathrm{j}$.

As the Slutsky coefficient is defined as $\pi_{\mathrm{ij}}=\left(\mathrm{p}_{\mathrm{i}} \mathrm{p}_{\mathrm{j}} / \mathrm{M}\right) \mathrm{s}_{\mathrm{ij}}$. we multiply both sides of (4.2) by $\mathrm{p}_{\mathrm{i}} \mathrm{p}_{\mathrm{j}} / \mathrm{M}$ to yield

$$
\pi_{\mathrm{ij}}=v_{\mathrm{ij}}-\phi \theta_{\mathrm{i}} \theta_{\mathrm{j}},
$$

where $v_{\mathrm{ij}}=(\lambda / \mathrm{M}) \mathrm{p}_{\mathrm{i}} \mathrm{p}_{\mathrm{j}} \mathrm{u}^{\mathrm{ij}}$ and $\phi=(\partial \log \lambda / \partial \log \mathrm{M})^{-1}<0$ is the reciprocal of the income elasticity of the marginal utility of income, which is known as the income flexibility, and $\theta_{i}=\partial\left(p_{i} q_{i}\right) / \partial M$ is the marginal share of $\mathrm{i}$, as before. The $v_{\mathrm{ij}}$ are obviously symmetric in $\mathrm{i}$ and $\mathrm{j}$ and satisfy

$$
\sum_{j=1}^{n} v_{i j}=\phi \theta_{i}, i=1, \ldots, n
$$

Using (4.4), the substitution term in equation (4.1) becomes

$$
\sum_{j=1}^{n} \pi_{i j} d\left(\log p_{j}\right)=\sum_{j=1}^{n} v_{i j} d\left(\log p_{j}\right)-\phi \theta_{i} \sum_{j=1}^{n} \theta_{j} d\left(\log p_{j}\right)=\sum_{j=1}^{n} v_{i j}\left[d\left(\log p_{j}\right)-d\left(\log P^{\prime}\right)\right],
$$

where $d\left(\log \mathrm{P}^{\prime}\right)=\sum_{\mathrm{i}=1}^{\mathrm{n}} \theta_{\mathrm{i}} \mathrm{d}\left(\log \mathrm{p}_{\mathrm{i}}\right)$ is the Frisch (1932) price index. Like its Divisia counterpart, the Frisch index is a weighted average of prices, but now the weights are marginal shares, rather than budget shares. Relative to Divisia, luxuries are more heavily weighted in the Frisch index, and vice versa for necessities.

The $i^{\text {th }}$ demand equation in relative prices takes the form

$$
\mathrm{w}_{\mathrm{i}} \mathrm{d}\left(\log \mathrm{q}_{\mathrm{i}}\right)=\theta_{\mathrm{i}} \mathrm{d}(\log \mathrm{Q})+\sum_{\mathrm{j}=1}^{\mathrm{n}} \mathrm{v}_{\mathrm{ij}}\left[\mathrm{d}\left(\log \mathrm{p}_{\mathrm{j}}\right)-\mathrm{d}\left(\log \mathrm{P}^{\prime}\right)\right] .
$$

This formulation is the relative price version of equation (4.1) and shows that the $v_{\mathrm{ij}}$ are price coefficients. Here, the general substitution effect acts as the deflator of $d\left(\log \mathrm{p}_{\mathrm{j}}\right)$ to isolate the specific effect. Dividing both sides of equation (4.5) by $\mathrm{w}_{\mathrm{i}}$, it can be seen that $\theta_{\mathrm{i}} / \mathrm{w}_{\mathrm{i}}$ is the income elasticity of demand for good $\mathrm{i}$ and $\mathrm{v}_{\mathrm{ij}} / \mathrm{w}_{\mathrm{i}}$ is the elasticity of demand for good $\mathrm{i}$ with respect to the $\mathrm{j}^{\text {th }}$ relative price. This price elasticity holds constant the marginal utility of income and is known as a Frisch elasticity. It follows from equation (4.4) that $\sum_{\mathrm{j}=1}^{\mathrm{n}} \mathrm{w}_{\mathrm{i}}\left(\mathrm{v}_{\mathrm{ij}} / \mathrm{w}_{\mathrm{i}}\right)=\phi \theta_{\mathrm{i}}$, so that a budget-share weighted average of the own- and cross-price Frisch elasticities of a good is proportional to its marginal share. Furthermore, as the marginal shares have a unit sum, summing both sides of this last equation over $\mathrm{i}=1, \ldots, \mathrm{n}$ gives $\sum_{\mathrm{i}=1}^{\mathrm{n}} \sum_{\mathrm{j}=1}^{\mathrm{n}} \mathrm{w}_{\mathrm{i}}\left(\mathrm{v}_{\mathrm{ij}} / \mathrm{w}_{\mathrm{i}}\right)=\phi$, which shows that the income flexibility $\phi$ is 
also interpreted as the sum of those weighted-average price elasticities. In other words, $\phi$ can be regarded as a measure of the overall degree of substitutability among the $n$ goods. Equation (4.5) forms the basis for what Theil (1980) calls the differential approach. ${ }^{11}$

The constancy of $\phi$ in the Rotterdam model could be considered to be another weakness. Frisch (1959, p. 189) famously conjectured that $\phi$ was not constant but rather it would increase in absolute value with income, from -0.1 for "the extremely poor and apathetic part of the population”, to -0.5 for "the middle income bracket, 'the median part' of the population", and end up at -10 for “the rich part of the population with ambitions towards 'conspicuous consumption' ". But as this conjecture is based on cardinal utility, it is considered to be of dubious/limited value. We shall return to this issue shortly.

As $v_{i j}=(\lambda / M) p_{i} p_{j} u^{i j}$, restrictions on preferences imply restrictions on these price coefficients. Under preference independence, for example, $\mathrm{u}^{\mathrm{ij}}=0, \mathrm{i} \neq \mathrm{j}$, so the corresponding price coefficients $v_{\mathrm{ij}}=0$; and from (4.4), $v_{\mathrm{ij}}=\phi \theta_{\mathrm{i}}$. The substitution term in (4.5) then becomes

$$
\sum_{j=1}^{n} v_{i j}\left[d\left(\log p_{j}\right)-d\left(\log P^{\prime}\right)\right]=\phi \theta_{i}\left[d\left(\log p_{j}\right)-d\left(\log P^{\prime}\right)\right]
$$

This shows that if the marginal utility of each good is independent of the consumption of all others, then the substitution part of each good's demand equation contains only the own relative price, not the others. This is an attractively simple result that links observed demand behaviour to the consumer's preferences. Generalisations involve utility being additive in (or some increasing function of) groups of goods. If, for example, food and alcoholic beverages constitute separate commodity groups in the utility function, then the demand for bread is independent of the price of beer.

The appeal of equation (4.5) is its transparent link to a general utility function, its clean split between the income and substitution effects (of both the specific and general varieties) and the ease of interpretation of its coefficients. The differential approach is general in the sense that the "coefficients" of demand equation (4.5) are not necessarily constant and that equation is consistent with any utility/cost function. As described above, the parameterisation decision (what is taken to be constant and what is variable) is delayed until the last moment - when the demand equations are estimated with actual data. The flexibility of the approach promotes constructive interaction between the data and the functional form of the demand equations.

\footnotetext{
${ }^{11}$ As earlier forerunners of the approach, Theil (1980, p. xi) acknowledges the work of Divisia (1925) on index numbers, Frisch (1959) on want independence (and some generalisations) and Gorman $(1959,1968)$ on separable utility.
} 
There is a further distinction between the relative price and absolute price formulations. It is clear from the derivation in Section 2 that model (4.1) -- absolute prices -- deals with the price slopes of the demand equations. These slopes involve a question of positive economics -- when real income remains unchanged, how does consumption of good i respond to a change in the price of $j$ ? The answer to this question is observable (or, at least, estimable) and thus independent of any monotonically increasing function of the underlying utility function. In other words, the underlying utility function is ordinal, not cardinal. The same is not true of the relative price version, model (4.5). The $(i, j)^{\text {th }}$ price coefficient in this model is $v_{i j}=(\lambda / M) p_{i} p_{j} u^{i j}$, where $u^{i j}$ is the $(i, j)^{\text {th }}$ element of the inverse of the Hessian matrix of the utility function. As the Hessian is not invariant to monotonic transformations, neither are the price coefficients. Another way to see the problem is to go back to equation (4.3), $\pi_{\mathrm{ij}}=v_{\mathrm{ij}}-\phi \theta_{\mathrm{i}} \theta_{\mathrm{j}}$, which expresses the Slutsky coefficient $\pi_{\mathrm{ij}}$ in terms of the price coefficient $v_{\mathrm{ij}}$. As $\pi_{\mathrm{ij}}$ is a simple transform of the price slope, it also is observable (in the above sense). This $\pi_{\mathrm{ij}}$ provides the value for the left-hand side of (4.3), while on the right, the marginal shares can also be "observed". That leaves the price coefficient $v_{\mathrm{ij}}$ and the income flexibility $\phi$ as unknowns. Their values are unknowable as there is insufficient information to identify the $v_{\mathrm{ij}}$ and $\phi$ separately -- their values depend upon which monotonic transformation of the utility function is chosen. Accordingly, the relative price version of the model, equation (4.5), is based on cardinal utility and is not identified without any further information.

One reaction to the identification/cardinality issue is to reject the relative price version completely and rely solely on the absolute price formulation. This is perfectly reasonable, but when the model is large (large n) there can be problems in estimating in an unrestricted fashion the correspondingly large number of Slutsky coefficients of the absolute price model. The relative price version under separability is a convenient way of reducing the dimensionality of the estimation problem by structuring the Slutsky coefficients. For example, under preference independence, $v_{i j}=0$ for $\mathrm{i} \neq \mathrm{j}$ and $v_{\mathrm{ii}}=\phi \theta_{\mathrm{i}}$, so that, from (4.3), $\pi_{\mathrm{ii}}=\phi \theta_{\mathrm{i}}\left(1-\theta_{\mathrm{i}}\right), \mathrm{i}=1, \ldots, \mathrm{n}$, and $\pi_{\mathrm{ij}}=-\phi \theta_{\mathrm{i}} \theta_{\mathrm{j}}, \mathrm{i} \neq \mathrm{j}$. These constraints lead to the substitution term under preference independence of the form given by equation (4.6). ${ }^{12}$

Additionally, the assumption of preference independence provides a useful interpretation of the income flexibility $\phi$. In this case, the Slutsky coefficients take the form $\pi_{\mathrm{ij}}=\phi \theta_{\mathrm{i}}\left(\delta_{\mathrm{ij}}-\theta_{\mathrm{j}}\right)$, where

\footnotetext{
${ }^{12}$ For a further discussion of the identifiability of the relative price version of the Rotterdam model, see Theil (1975/76, vol. 1, pp. 50-56).
} 
$\delta_{\mathrm{ij}}$ is the Kronecker delta $\left(\delta_{\mathrm{ij}}=1\right.$ if $\mathrm{i}=\mathrm{j}, 0$ otherwise $)$. As $\sum_{\mathrm{i}=1}^{\mathrm{n}} \theta_{\mathrm{i}}=1$, each $\theta_{\mathrm{i}}$ is of the order $1 / \mathrm{n}$. Thus, the product $\theta_{\mathrm{i}} \theta_{\mathrm{j}} \approx 0$, so that $\pi_{\mathrm{ii}} \approx \phi \theta_{\mathrm{i}}, \mathrm{i}=1, \ldots, \mathrm{n}$, and $\pi_{\mathrm{ij}} \approx 0, \mathrm{i} \neq \mathrm{j}$. Defining $\eta_{\mathrm{ii}}=\pi_{\mathrm{ii}} / \mathrm{w}_{\mathrm{i}}$ and $\eta_{\mathrm{i}}=\theta_{\mathrm{i}} / \mathrm{w}_{\mathrm{i}}$ as the own-price and income elasticities, we have $\eta_{\mathrm{ii}} \approx \phi \eta_{\mathrm{i}}, \mathrm{i}=1, \ldots, \mathrm{n}$. Accordingly, under preference independence, price elasticities are proportional to income elasticities, so that luxuries $\left(\eta_{i}>1\right)$ are more price elastic than necessities $\left(\eta_{i}<1\right)$. Deaton (1974) refers to a variant of this proportionality relationship as "Pigou's (1910) law". This would seem to agree with the intuitive idea that necessities (luxuries) tend to be essential (discretionary) goods, which have few (many) substitutes.

The proportionality relationship implies that $\phi \approx \eta_{\mathrm{ii}} / \eta_{\mathrm{i}}, \mathrm{i}=1, \ldots, \mathrm{n}$, so that the income flexibility emerges as the common ratio of the price elasticity to the corresponding income elasticity. As these elasticities are observable, so is their ratio. This means that under preference independence, the income flexibility is not dependent on monotonic transformations and is an ordinal concept. The assumption of preference independence is sufficient to identify the relative price model as that assumption restricts monotonically increasing transformations of the utility function to linear transformations. Estimated values of the income flexibility almost invariably come from models exhibiting preference independence. These values tend to be clustered around $-1 / 2$, which can be interpreted as saying that, on average, own-price elasticities are about one-half the corresponding income elasticities. ${ }^{13}$

In a related approach, the relative price model can be identified by fixing the value of the income flexibility at some a priori value (such as -1/2). The price coefficients recovered in this way can form the basis for a preliminary analysis of how goods might interact with each other and whether preferences might be separable. For an example of this approach, see Clements and S. Selvanathan (1991).

\section{A UNIFICATION OF ALTERNATIVE FUNCTIONAL FORMS}

This section illustrates the workings of the differential approach as a general mode of analysis by applying it to the Almost Ideal Demand System (AIDS, Deaton and Muellbauer 1980a), which

\footnotetext{
${ }^{13}$ In a review of older findings, Brown and Deaton (1972, p. 1206) conclude that "there would seem to be fair agreement on the use of a value for $\phi$ around minus one half". For a more recent survey that reaches the same broad conclusion, see Clements and Zhao (2009, pp. 227-29). From the budget constraint, the "average" commodity has a unity income elasticity, so $\phi=-1 / 2$ leads to the "folk theorem" that price elasticities for broad aggregates are approximately equal to minus one half (Clements, 2008). In this context, it is also worthwhile to note that Powell (1992) shows that under preference independence the average elasticity of substitution $\sigma \approx-\phi$. Interestingly, in an early paper, Leser (1960) actually set each pairwise $\sigma$ (and thus their average) at $1 / 2$ on the basis that this was about midway between his two initial estimates of 0.60 and 0.39 .
} 
according to Figure 1, is the most highly cited model over the past two decades. The general principle can also be applied to other demand models, as will be indicated later in this section.

The cost function refers to the minimum cost of obtaining a specified level of utility (u) given the price vector $(\mathbf{p})$, written c $(u, \mathbf{p})$. Deaton and Muellbauer (1980a) suggested a specific form of the logarithmic cost function

$$
\log c=a(\mathbf{p})+u \cdot b(\mathbf{p}),
$$

where $\mathrm{a}(\mathbf{p})=\sum_{\mathrm{i}=1}^{\mathrm{n}} \alpha_{\mathrm{i}}\left(\log \mathrm{p}_{\mathrm{i}}\right)+(1 / 2) \sum_{\mathrm{i}=1}^{\mathrm{n}} \sum_{\mathrm{j}=1}^{\mathrm{n}} \beta_{\mathrm{ij}}^{*}\left(\log \mathrm{p}_{\mathrm{i}}\right)\left(\log \mathrm{p}_{\mathrm{j}}\right)$ and $\mathrm{b}(\mathbf{p})=\gamma_{0} \Pi_{\mathrm{i}=1}^{\mathrm{n}} \mathrm{p}_{\mathrm{i}}^{\gamma_{\mathrm{i}}}$ with constants $\alpha_{i}, \quad \beta_{i j}^{*}, \quad \gamma_{0}$ and $\gamma_{i}, \quad i, j=1, \ldots, n$. . The corresponding indirect utility function is $\mathrm{u}_{\mathrm{I}}(\mathrm{M}, \mathbf{p})=[\log \mathrm{M}-\mathrm{a}(\mathbf{p})] / \mathrm{b}(\mathbf{p})$, so that the marginal utility of income and the income flexibility are

$$
\lambda=\frac{\partial \mathrm{u}_{\mathrm{I}}}{\partial \mathrm{M}}=[\mathrm{b}(\mathbf{p}) \mathrm{M}]^{-1} \text { and } \phi=\left(\frac{\partial \log \lambda}{\partial \log \mathrm{M}}\right)^{-1}=-1 .
$$

Thus, like the Rotterdam model, the income flexibility is a constant; but unlike the Rotterdam model, this is not a free parameter here as it is constrained to take the value -1 .

Using Shephard's lemma, the demand system is:

$$
\mathrm{w}_{\mathrm{i}}=\alpha_{\mathrm{i}}+\gamma_{\mathrm{i}} \log \left(\frac{\mathrm{M}}{\mathrm{P}^{*}}\right)+\sum_{\mathrm{j}=1}^{\mathrm{n}} \beta_{\mathrm{ij}}\left(\log \mathrm{P}_{\mathrm{j}}\right), \mathrm{i}=1, \ldots, \mathrm{n},
$$

where $\beta_{\mathrm{ij}}=\left(\beta_{\mathrm{ij}}^{*}+\beta_{\mathrm{ji}}^{*}\right) / 2$. Here, money income $\mathrm{M}$ is deflated by a price index $\mathrm{P}^{*}$, which is defined in $\operatorname{logarithmic~form~as~} \log \mathrm{P}^{*}=\sum_{\mathrm{i}=1}^{\mathrm{n}} \alpha_{\mathrm{i}}\left(\log \mathrm{p}_{\mathrm{i}}\right)+(1 / 2) \sum_{\mathrm{i}=1}^{\mathrm{n}} \sum_{\mathrm{j}=1}^{\mathrm{n}} \beta_{\mathrm{ij}}\left(\log \mathrm{p}_{\mathrm{i}}\right)\left(\log \mathrm{p}_{\mathrm{j}}\right)$. The implied marginal shares and income elasticities are

$$
\theta_{\mathrm{i}}=\frac{\partial \mathrm{w}_{\mathrm{i}} \mathrm{M}}{\partial \mathrm{M}}=\mathrm{w}_{\mathrm{i}}+\gamma_{\mathrm{i}} \text { and } \eta_{\mathrm{i}}=1+\frac{\gamma_{\mathrm{i}}}{\mathrm{w}_{\mathrm{i}}}, \mathrm{i}=1, \ldots, \mathrm{n} \text {. }
$$

For necessities $\left(\eta_{i}<1\right), \gamma_{i}$ is negative and $\theta_{i}<w_{i}$, and vice versa for luxuries. Both $\theta_{i}$ and $\eta_{i}$ are variable, satisfying $d \theta_{\mathrm{i}}=\mathrm{dw}_{\mathrm{i}}$ and $\mathrm{d} \eta_{\mathrm{i}}=-\gamma_{\mathrm{i}} \mathrm{dw} \mathrm{w}_{\mathrm{i}} / \mathrm{w}_{\mathrm{i}}^{2}$

The differential of equation (5.1) is

$$
d w_{i}=\gamma_{i}\left[d(\log M)-d\left(\log P^{*}\right)\right]+\sum_{j=1}^{n} \beta_{i j} d\left(\log p_{j}\right)
$$

Since $d w_{i}=w_{i} d\left(\log p_{i}\right)+w_{i} d\left(\log q_{i}\right)-w_{i} d(\log M)$, the quantity component of the change in the budget share is obtained by subtracting $\mathrm{w}_{\mathrm{i}} \mathrm{d}\left(\log \mathrm{p}_{\mathrm{i}}\right)-\mathrm{w}_{\mathrm{i}} \mathrm{d}(\log \mathrm{M})$ from both sides of (5.2):

$$
w_{i} d\left(\log q_{i}\right)=\left(\gamma_{i}+w_{i}\right) d(\log M)-\gamma_{i} d\left(\log P^{*}\right)+\sum_{j=1}^{n}\left(\beta_{i j}-w_{i} \delta_{i j}\right) d\left(\log p_{j}\right),
$$


where $\delta_{\mathrm{ij}}$ is the Kronecker delta $\left(\delta_{\mathrm{ij}}=1 \mathrm{if} \mathrm{i}=\mathrm{j}, 0\right.$ otherwise $)$. Recall from Section 2 that the differential of the budget constraint can be expressed as $d(\log M)=d(\log P)+d(\log Q)$, where $\mathrm{d}(\log \mathrm{P})$ and $\mathrm{d}(\log \mathrm{Q})$ are Divisia indexes of prices and quantities. Therefore, the right-hand side of equation (5.3) can be written as the sum of two parts: (i) A term involving the change in real income $\left(\gamma_{\mathrm{i}}+\mathrm{w}_{\mathrm{i}}\right) \mathrm{d}(\log \mathrm{Q})=\theta_{\mathrm{i}} \mathrm{d}(\log \mathrm{Q})$, where the marginal share $\theta_{\mathrm{i}}=\gamma_{\mathrm{i}}+\mathrm{w}_{\mathrm{i}}$, as above. (ii) The substitution term

$$
\begin{gathered}
\left(\gamma_{i}+w_{i}\right) d(\log P)-\gamma_{i} d\left(\log P^{*}\right)+\sum_{j=1}^{n}\left(\beta_{i j}-w_{i} \delta_{i j}\right) d\left(\log p_{j}\right) \\
=\sum_{j=1}^{n}\left[\left(\gamma_{i}+w_{i}\right) w_{j}-\gamma_{i} \alpha_{j}-\gamma_{i} \sum_{k=1}^{n} \beta_{k j} \log p_{k}+\beta_{i j}-\delta_{i j} w_{i}\right] d\left(\log p_{j}\right)=\sum_{j=1}^{n}\left[\beta_{i j}+w_{i}\left(w_{j}-\delta_{i j}\right)+\gamma_{i} \gamma_{j} \log \left(\frac{M}{P^{*}}\right)\right] d\left(\log p_{j}\right),
\end{gathered}
$$

where the second step follows from equation (5.1). Combining the two terms, equation (5.3) becomes

$$
\left\{\begin{aligned}
\mathrm{w}_{\mathrm{i}} \mathrm{d}\left(\log \mathrm{q}_{\mathrm{i}}\right) & =\left(\gamma_{\mathrm{i}}+\mathrm{w}_{\mathrm{i}}\right) \mathrm{d} \log \mathrm{Q}+\sum_{\mathrm{j}=1}^{\mathrm{n}}\left[\beta_{\mathrm{ij}}+\mathrm{w}_{\mathrm{i}}\left(\mathrm{w}_{\mathrm{j}}-\delta_{\mathrm{ij}}\right)+\gamma_{\mathrm{i}} \gamma_{\mathrm{j}} \log \left(\frac{\mathrm{M}}{\mathrm{P}^{*}}\right)\right] \mathrm{d}\left(\log \mathrm{p}_{\mathrm{j}}\right) \\
& =\theta_{\mathrm{i}} \mathrm{d}(\log \mathrm{Q})+\sum_{\mathrm{j}=1}^{\mathrm{n}} \pi_{\mathrm{ij}} \mathrm{d}\left(\log \mathrm{p}_{\mathrm{j}}\right),
\end{aligned}\right.
$$

where $\pi_{\mathrm{ij}}=\beta_{\mathrm{ij}}+\mathrm{w}_{\mathrm{i}}\left(\mathrm{w}_{\mathrm{j}}-\delta_{\mathrm{ij}}\right)+\gamma_{\mathrm{i}} \gamma_{\mathrm{j}} \log \left(\mathrm{M} / \mathrm{P}^{*}\right)$ is the $(\mathrm{i}, \mathrm{j})^{\text {th }}$ Slutsky coefficient. It is clear this $\pi_{\mathrm{ij}}$ is not a constant, and varies with budget shares of goods $\mathrm{i}$ and $\mathrm{j}$, as well as real income. These coefficients satisfy $\sum_{\mathrm{j}=1}^{\mathrm{n}} \pi_{\mathrm{ij}}=0$ and $\pi_{\mathrm{ij}}=\pi_{\mathrm{ji}}$. Equation (5.4) is exactly the same as (4.1), the infinitesimal version of the absolute price version of the Rotterdam model; clearly both models are members of the differential demand family.

To derive the relative price version, add and subtract $\phi \theta_{i} \sum_{j=1}^{n} \theta_{j} d\left(\log p_{j}\right)$ from the right-hand side of the second line of (5.4). This yields

$$
\left\{\begin{aligned}
\mathrm{w}_{\mathrm{i}} \mathrm{d}\left(\log \mathrm{q}_{\mathrm{i}}\right) & =\theta_{\mathrm{i}} \mathrm{d}(\log \mathrm{Q})+\sum_{\mathrm{j}=1}^{\mathrm{n}}\left(\pi_{\mathrm{ij}}+\phi \theta_{\mathrm{i}} \theta_{\mathrm{j}}\right) \mathrm{d}\left(\log \mathrm{p}_{\mathrm{j}}\right)-\phi \theta_{\mathrm{i}} \sum_{\mathrm{j}=1}^{\mathrm{n}} \theta_{\mathrm{j}} \mathrm{d}\left(\log \mathrm{p}_{\mathrm{j}}\right) \\
& =\theta_{\mathrm{i}} \mathrm{d}(\log \mathrm{Q})+\sum_{\mathrm{j}=1}^{\mathrm{n}}\left(\pi_{\mathrm{ij}}+\phi \theta_{\mathrm{i}} \theta_{\mathrm{j}}\right)\left[\mathrm{d}\left(\log \mathrm{p}_{\mathrm{j}}\right)-\mathrm{d}\left(\log \mathrm{P}^{\prime}\right)\right] \\
& =\theta_{\mathrm{i}} \mathrm{d}(\log \mathrm{Q})+\sum_{\mathrm{j}=1}^{\mathrm{n}} \mathrm{v}_{\mathrm{ij}}\left[\mathrm{d}\left(\log \mathrm{p}_{\mathrm{j}}\right)-\mathrm{d}\left(\log \mathrm{P}^{\prime}\right)\right],
\end{aligned}\right.
$$

where the second step follows from $\sum_{\mathrm{j}=1}^{\mathrm{n}} \pi_{\mathrm{ij}}=0$ and $\sum_{\mathrm{j}=1}^{\mathrm{n}} \phi \theta_{\mathrm{i}} \theta_{\mathrm{j}}=\phi \theta_{\mathrm{i}}$. As before, the term $d\left(\log P^{\prime}\right)=\sum_{j=1}^{n} \theta_{j} d\left(\log p_{j}\right)$ is the Frisch price index, while $v_{i j}$ is the $(i, j)^{\text {th }}$ price coefficient, defined as 


$$
v_{\mathrm{ij}}=\beta_{\mathrm{ij}}+\mathrm{w}_{\mathrm{i}}\left(\mathrm{w}_{\mathrm{j}}-\delta_{\mathrm{ij}}\right)+\gamma_{\mathrm{i}} \gamma_{\mathrm{j}} \log \left(\frac{\mathrm{M}}{\mathrm{P}^{*}}\right)-\theta_{\mathrm{i}} \theta_{\mathrm{j}}
$$

As indicated above, $\phi=-1$ in AIDS, so expression (5.6) is consistent with constraints (4.3) and (4.4). As equation (5.5) has the same form as (4.5), this establishes that AIDS can also be expressed as a differential demand system in relative prices.

Following a similar approach, other demand models can also be expressed as particular parameterisations of the differential system. Table 1 illustrates by giving expressions for coefficients of the differential system implied by five other widely used models. ${ }^{14}$ The corresponding levels demand equations can be recovered by integration. In this sense, the differential system represents a generalised approach to demand analysis. As can be seen, the Rotterdam model (panel F of Table 1) is the simplest example of the general differential demand system: According to this model, the coefficients of equations (4.1) and (4.5) -- the marginal shares, Slutsky coefficients, income flexibility and price coefficients -- are all constants. This has the attraction of transparency and simplicity, but as discussed in Section 3, the constancy of the marginal shares can be problematic, especially for food when there are large variations in income.

Table 1 shows how it is possible to interpret the parameters of other models in terms of those of the Rotterdam and vice versa. This link between the Rotterdam and other models reveals that despite its unorthodox derivation, the Rotterdam is really more familiar than might first seem to be the case. It should be mentioned that there are two other popular models related to the Rotterdam -the CBS model (Keller and van Driel, 1985) and the NBR model (Neves, 1987).

Choosing between different demand models is not an easy task as it involves often conflicting criteria. Agreement with microeconomic theory, flexibility, tractability and ease of interpretation are all desirable attributes that have been emphasised above. The ability of a model to fit the data is an additional important consideration. Several of the demand models of Table 1 have been compared on the basis of their goodness-of-fit by, for example, Klevmarken (1979), Parks (1969) and Theil $(1975 / 76)$. Denote the budget shares of the $n$ goods in period $t$ implied by the model by $\hat{w}_{1 t}, \ldots, \hat{w}_{n t}$, while the observed shares are $\mathrm{w}_{1 \mathrm{t}}, \ldots, \mathrm{w}_{\mathrm{nt}}$. As the demand model refers to the whole budget, these two vectors as a whole need to be compared. One way to do this for all $t=1, \ldots$, T observations is with the average information inaccuracy, $(1 / \mathrm{T}) \Sigma_{\mathrm{t}=1}^{\mathrm{T}} \Sigma_{\mathrm{i}=1}^{\mathrm{n}} \mathrm{W}_{\mathrm{it}} \log \left(\mathrm{w}_{\mathrm{it}} / \hat{\mathrm{w}}_{\mathrm{it}}\right)$, which measures the lack of fit of the model. A new approach to model evaluation, due to Barnett and Kanyama (2013) and Barnett and Seck (2008), uses Monte Carlo techniques to show that under most circumstances the Rotterdam model performs better than the AIDS model.

\footnotetext{
${ }^{14}$ See Clements and Gao (2014) for detailed derivations.
} 


\section{FROM TIME TO SPACE: CROSS-COUNTRY DEMAND ANALYSIS}

The Rotterdam model deals with the change in consumption over time. But the underlying differential approach deals with any kind of displacement, no matter what the source; thus, the approach has also been used for the analysis of consumption patterns in different countries. Compared with time-series data, cross-country data exhibit substantially more variability in income and prices. For example, some of the poorest countries devote substantially more than one-half of income to food consumption, while in the richest, food absorbs less than 10 percent. This diversity provides the opportunity for more precise estimates of key demand parameters. But it also presents a challenge: Can the utility-maximisation model possibly explain these vast differences without resorting to the ad hocery of "special factors" that allegedly influence the pattern of demand in one or more countries? Relatedly, can tastes be taken to be sufficiently similar so that the same demand model can be applied to all countries, no matter how they differ in affluence and/or in the structure of prices? The key references regarding the adaption of the Rotterdam approach to cross-country comparisons are Clements and Theil (1979), Theil and Suhm (1981), Theil (1987), Theil et al. (1989) and Seale and Regmi (2006). ${ }^{15}$ This section, which is based on Theil et al. (1989), is a brief overview of some of these developments.

The starting point is equation (4.1), the differential demand equation for good $\mathrm{i}$ in absolute prices, $\quad \mathrm{w}_{\mathrm{i}} \mathrm{d}\left(\log \mathrm{q}_{\mathrm{i}}\right)=\theta_{\mathrm{i}} \mathrm{d}(\log \mathrm{Q})+\sum_{\mathrm{j}=1}^{\mathrm{n}} \pi_{\mathrm{ij}} \mathrm{d}\left(\log \mathrm{p}_{\mathrm{j}}\right)$. For country c, when income is fixed at $\log \mathrm{Q}_{\mathrm{c}}$, the first term on the right vanishes. Combining this with the change in the budget share for c, $\mathrm{dw}_{\mathrm{ic}}=\mathrm{w}_{\text {ic }}\left[\mathrm{d}\left(\log \mathrm{p}_{\mathrm{ic}}\right)-\mathrm{d}\left(\log \mathrm{P}_{\mathrm{c}}\right)\right]+\mathrm{w}_{\mathrm{ic}} \mathrm{d}\left(\log \mathrm{q}_{\mathrm{ic}}\right)$, gives

$$
\mathrm{dw}_{\mathrm{ic}}=\mathrm{w}_{\mathrm{ic}}\left[\mathrm{d}\left(\log \mathrm{p}_{\mathrm{ic}}\right)-\mathrm{d}\left(\log \mathrm{P}_{\mathrm{c}}\right)\right]+\sum_{\mathrm{j}=1}^{\mathrm{n}} \pi_{\mathrm{ij}} \mathrm{d}\left(\log \mathrm{p}_{\mathrm{jc}}\right) \text {, }
$$

where $d\left(\log P_{c}\right)=\sum_{j=1}^{n} w_{j c} d\left(\log p_{j c}\right)$ is the Divisia price index. Suppose there are $c=1, \ldots, C$ countries. Define the world price of good i as the geometric mean over countries (to be denoted by $\left.\overline{\mathrm{p}}_{\mathrm{i}}\right), \tilde{\mathrm{q}}_{\mathrm{ic}}$ as the quantity of good i consumed in country c evaluated at c's real income and these world

\footnotetext{
${ }^{15}$ Other related research includes Barten (1989), Chen (1999), Clements and S. Selvanathan (1994), Gao (2012), Meade et al. (2014), Muhammad et al. (2011), Regmi and. Seale (2010), Seale et al. (1991), Seale et al. (2003), Seale and Regmi (2006, 2009), Seale and Solano (2012), E. A. Selvanathan and S. Selvanathan (2003), S. Selvanathan (1991, 1993), S. Selvanathan and E. A. Selvanathan (1994) and Theil (1996). Consumption economics has, of course, long had an international flavour; influential cross-country studies that use other approaches to demand modelling include Goldberger and Gamaletsos (1970), Houthakker (1957, 1965), Kravis et al. (1982, Chap 9), Lluch and Powell (1975), Lluch et al. (1977), Parks and Barten (1973), Pollak and Wales (1987) and Rimmer and Powell (1992).
} 
prices, and $\tilde{\mathrm{W}}_{\mathrm{ic}}$ as the corresponding budget share. If $\mathrm{dW}_{\mathrm{ic}}$ is interpreted as $\mathrm{W}_{\mathrm{ic}}-\tilde{\mathrm{W}}_{\mathrm{ic}}$, and $\mathrm{d}\left(\log \mathrm{p}_{\mathrm{ic}}\right)$ as $\log \mathrm{p}_{\mathrm{ic}}-\log \overline{\mathrm{p}}_{\mathrm{i}}$, then from the mean value theorem, equation (6.1) becomes

$$
\mathrm{w}_{\mathrm{ic}}-\tilde{\mathrm{w}}_{\mathrm{ic}}=\tilde{\mathrm{w}}_{\mathrm{ic}}\left[\log \left(\frac{\mathrm{p}_{\mathrm{ic}}}{\overline{\mathrm{P}}_{\mathrm{i}}}\right)-\sum_{\mathrm{j}=1}^{\mathrm{n}} \tilde{\mathrm{w}}_{\mathrm{jc}} \log \left(\frac{\mathrm{p}_{\mathrm{jc}}}{\overline{\mathrm{p}}_{\mathrm{j}}}\right)\right]+\sum_{\mathrm{j}=1}^{\mathrm{n}} \pi_{\mathrm{ij}} \log \left(\frac{\mathrm{p}_{\mathrm{jc}}}{\overline{\mathrm{p}}_{\mathrm{j}}}\right) .
$$

The first term on the right-hand side of this equation recognises that a higher relative price raises expenditure on the good when the consumer buys the same quantity despite its higher price; this leads to an increase in the budget share. The second term deals with the substitution effect whereby the consumer buys less of good i following a price increase, and more other goods (on average, at least).

Equation (6.2) holds real income constant. The budget share $\tilde{\mathrm{w}}_{\mathrm{ic}}$ here is evaluated at country c's real income and the world average prices. Theil et al. (1989) allow for income to differ across countries by using Working's (1943) model, $\tilde{\mathrm{w}}_{\mathrm{ic}}=\alpha_{\mathrm{i}}+\beta_{\mathrm{i}} \log \mathrm{Q}_{\mathrm{c}} \cdot{ }^{16}$ Combining this with equation (6.2) gives

$$
\mathrm{w}_{\mathrm{ic}}=\alpha_{\mathrm{i}}+\beta_{\mathrm{i}} \log \mathrm{Q}_{\mathrm{c}}+\tilde{\mathrm{w}}_{\mathrm{ic}}\left[\log \left(\frac{\mathrm{p}_{\mathrm{ic}}}{\overline{\mathrm{p}}_{\mathrm{i}}}\right)-\sum_{\mathrm{j}=1}^{\mathrm{n}} \tilde{\mathrm{w}}_{\mathrm{jc}} \log \left(\frac{\mathrm{p}_{\mathrm{jc}}}{\overline{\mathrm{p}}_{\mathrm{j}}}\right)\right]+\sum_{\mathrm{j}=1}^{\mathrm{n}} \pi_{\mathrm{ij}} \log \left(\frac{\mathrm{p}_{\mathrm{jc}}}{\overline{\mathrm{p}}_{\mathrm{j}}}\right) .
$$

Finally, to avoid over-parameterisation, preference independence is assumed, which means that the Slutsky coefficients take the form $\pi_{\mathrm{ij}}=\phi \theta_{\mathrm{i}}\left(\delta_{\mathrm{ij}}-\theta_{\mathrm{j}}\right)$. Then, as the marginal shares in Working's model are $\theta_{\text {ic }}=\mathrm{w}_{\text {ic }}+\beta_{\mathrm{i}}$, the above becomes

$$
\mathrm{w}_{\mathrm{ic}}=\alpha_{\mathrm{i}}+\beta_{\mathrm{i}} \log \mathrm{Q}_{\mathrm{c}}+\tilde{\mathrm{w}}_{\mathrm{ic}}\left[\log \left(\frac{\mathrm{p}_{\mathrm{ic}}}{\overline{\mathrm{p}}_{\mathrm{i}}}\right)-\sum_{\mathrm{j}=1}^{\mathrm{n}} \tilde{\mathrm{w}}_{\mathrm{jc}} \log \left(\frac{\mathrm{p}_{\mathrm{jc}}}{\overline{\mathrm{p}}_{\mathrm{j}}}\right)\right]+\phi\left(\tilde{\mathrm{w}}_{\mathrm{ic}}+\beta_{\mathrm{i}}\right)\left[\log \left(\frac{\mathrm{p}_{\mathrm{ic}}}{\overline{\mathrm{p}}_{\mathrm{i}}}\right)-\sum_{\mathrm{j}=1}^{\mathrm{n}}\left(\tilde{\mathrm{w}}_{\mathrm{jc}}+\beta_{\mathrm{j}}\right) \log \left(\frac{\mathrm{p}_{\mathrm{jc}}}{\overline{\mathrm{p}}_{\mathrm{j}}}\right)\right] \text {. }
$$

Equation (6.3) is known as the Working-PI model, where PI stands for preference independence. ${ }^{17}$ This model contains Working's $\alpha_{i}$ and $\beta_{i}$ plus and a constant income flexibility $\phi$, a total of $2(n-1)+1$ parameters. As the coefficients are taken to be the same in different countries, tastes are assumed to be the same internationally. Theil and his co-authors argue that tastes are less likely to be substantially different when broad commodity groups are used. Thus, for example, Theil and Suhm (1981, pp. 1-2) state:

\footnotetext{
${ }^{16}$ Other functional forms, such as the logistic and reciprocal, are analysed in Gao (2012) who places particular emphasis on the form of the Engel curve for food.

${ }^{17}$ More recently, this has been referred to as the Florida-PI model (Muhammad et al., 2011), in recognition of the location of much research on cross-country consumption comparisons in general and the development of this particular model.
} 
The underlying assumption is that "all countries are the same" in the sense that their per capita consumption of goods and services can be viewed as being generated by essentially the same consumer preferences. If this assumption is acceptable, the only (but major!) differences between countries result from their differences in income and prices, apart possibly from random effects. But this assumption immediately raises the objection that different nations have different cultures. We should expect that Indians spend little on meat and, indeed, the data produced by Kravis et al. [1982] confirm that this is so. The appropriate answer is that a cross-country demand system should be constructed, not for a very large number of detailed consumption categories, but only for a modest number of much broader categories. Accordingly, meat is part of a "good" called Food ... ${ }^{18}$

The assumption of preference independence that is embodied in (6.3) is also likely to be more suitable when applied to broad aggregates.

\section{CONCLUDING COMMENTS}

Most economists are now familiar with Deaton and Muellbauer's (1980a) Almost Ideal Demand System (AIDS). This is a system of $n$ demand equations whose form is obtained from an algebraic specification of the consumer's cost function, which can be thought of as an approximation to the unknown true form. Similarly, the translog system (Christensen et al., 1975) comes from a specification of the indirect utility function, while the linear expenditure system (LES, Stone, 1954) derives from a specific direct utility function. Less familiar is the approach of the Rotterdam model (Barten, 1964, Theil, 1965). Here, the precise form of the function to be optimised (the cost or utility function) is left unspecified, but the general constraints of the utility-maximisation problem of homogeneity (the absence of money illusion) and symmetry of the substitution effects are incorporated into the demand equations. Working with a straightforward transform of demand equations expressed in terms of differences in the logarithms (weighting them by the corresponding budget shares), these constraints take the convenient form of linear parametric restrictions. The question of functional form is therefore left until the last step in the Rotterdam approach, rather than the first as in other approaches. The Rotterdam demand equations are thus interpreted as approximations to the true, unknown ones. These demand equations provide a simple way to test the theory of consumer demand, as well as the separability of preferences. The transparency of the

\footnotetext{
${ }^{18}$ The assumption that tastes are constant is a major element of Chicago economics as practiced by Becker, Freidman and Stigler (Friedman, 1962, Stigler and Becker, 1977). Interestingly, while at Chicago, Theil's approach to this issue seemed to evolve as earlier he argued that it was perfectly acceptable for tastes to be different in different countries: When describing the results from two independent applications of the Rotterdam model to Dutch and British time-series data with $n=4$ goods, Theil (1975/76, vol.1, p. 208) writes "[t]he income elasticities of food agree with each other and they are of the order of magnitude which one would expect them to be, but the elasticities of the three other commodity groups show larger differences. There is no reason to be apologetic about this result, since different nations may have different preferences.” S. Selvanathan $(1991,1993)$ provides evidence that points towards the similarity across countries and regions of tastes for broad aggregates.
} 
approach, and its generality, has contributed to the prominence of the Rotterdam model over the past half-century. Some of the major events in the development of the model and its descendants are listed in Table 2.

The 1960s were a period of rapid developments in econometrics with many breakthroughs, one of which was the Rotterdam demand model. Interestingly, this occurred in Rotterdam, not at either of the two Cambridges, that, at the time, laid claims to global leadership in economic research. Why/how did this occur in the second city of a small, non-English-speaking country still recovering from the ravages of war? Whatever the reason for this seemingly unlikely event, Barten and Theil had the prescience to come up with an elegantly simple model that has stood the test of time and their Rotterdam model is now one of the workhorses of applied demand analysis. ${ }^{19}$

There is still some lingering resistance to the model due to doubts about its microeconomic foundations and the unconventional nature of its derivation. In marking the model's golden jubilee, this paper has emphasised its strong link with preferences and utility maximisation, highlighted its strengths and weaknesses and shown how it has opened up new opportunities for creative research in the form of the differential approach and cross-country consumption economics. By devoting considerable attention to the derivation and interpretation of the model, our objective has been to enhance understanding and make the Rotterdam system more accessible to economists. The paper also emphasised that like all models, the Rotterdam is not perfect and involves familiar trade-offs between generality, tractability and ease of interpretation.

The paper demonstrated how other popular models, including AIDS, LES and the translog, can be reformulated as differential systems that closely resemble the Rotterdam model. This shows that these more conventionally derived models are closer to the Rotterdam than might have been previously thought to be the case.

In addition to consumer demand, the model (or variants thereof) have been applied to a range of other areas, including labour economics, international trade, energy economics, marketing, the economics of advertising, forecasting, regional economics, monetary economics and the analysis of

\footnotetext{
${ }^{19}$ In discussion with Clements, Paul Frijters has pointed out that as the city of Rotterdam was a long-standing centre of international trade, English was widely spoken there in the 1960s and its scholars were well connected with the rest-ofthe-world academic community. He argues that research networks at that time centred more around individuals rather than locations. This can be taken to say that the physical/cultural/sociological aspects of 1960s Rotterdam were not particularly different from those of other centres of economic research. Perhaps the creation of the Rotterdam model in the context of Rotterdam of the 1960s was not as unlikely as implied by the text.

In correspondence with Clements, Ranjan Ray noted another historical aspect of the Rotterdam model that is of considerable practical relevance - its role in the development of the teaching of econometrics at the advanced level. Ray was a student at the Delhi School of Economics in the early 1970s and was taught by A. L. Nagar (1930- 2014), himself a Theil student in the late 1950s in Rotterdam. Nagar used the Rotterdam model to teach the SURE set up, something that also occurred at universities elsewhere. Ray states "even today, I find the Rotterdam model to be a handy tool to explain the use of 2SLS and 3SLS estimation methods”. Theil certainly used the model in teaching econometrics at Chicago, as is clear from his influential textbook Principles of Econometrics (Theil, 1971).
} 
market structure in industrial organisation. ${ }^{20}$ It seems likely that the Rotterdam model will continue to play an influential role in the future.

${ }^{20}$ A selection of studies in these areas is as follows: In labour economics, Barnett (1979a, 1981) and Kiefer (1977); international trade, Berner (1977), Theil and Clements (1978), Marquez (1994) and Seale et al. (1992); energy economics, Fiebig et al. (1987), Seale et al. (1991) and Seale and Solano (2012); marketing, Clements and E. A. Selvanathan (1988) and Vilcassim (1989); advertising, Duffy (1987) and E. A. Selvanathan (1989, 1995a,b); forecasting, E. A. Selvanathan (1995c); regional economics, S. Selvanathan (1991) and S. Selvanathan and E. A. Selvanathan (1994); monetary economics, Clements and Nguyen (1980), Fayyad (1986) and Offenbacher (1980); and industrial organisation, Capps et al. (2003). There have also been a numerous applications of the Rotterdam system to the demand for agricultural commodities. The inverse form of Rotterdam has prices on the left-hand side and quantities on the right (Barten and Bettendorf, 1989). This model has been extensively used for fresh food. Mixed systems (on the left, prices of some goods and the quantities of the others) have also been used (Barten, 1992, Moschini and Vissa, 1993). 


\section{References}

Barnett, W. A. (1979a). “The Joint Allocation of Goods and Leisure Expenditure.” Econometrica 47: 539-63.

Barnett, W. A. (1979b). “Theoretical Foundations for the Rotterdam Model.” Review of Economic Studies 45: 109-130.

Barnett, W. A. (1981). Consumer Demand and Labour Supply: Goods, Monetary Assets and Time. Amsterdam: North-Holland Publishing Company.

Barnett, W. A. (1984). “On the Flexibility of the Rotterdam Model: A First Empirical Look.” European Economic Review 24: 285-89.

Barnett, W. A. (2003), "A Conversation with Henri (Hans) Theil: His Experiences in the Netherlands during the Second World War.” Journal of Agricultural and Applied Economics 35 Supplement: 57.

Barnett, W. A., and I. Kanyama (2013). "Time-Varying Parameters in the Almost Ideal Demand System and the Rotterdam Model: Will the Best Specification Please Stand Up?” Applied Economics 45: 416983.

Barnett, W. A., and O. Seck (2008). "Rotterdam versus Almost Ideal Model: Will the Best Specification Please Stand Up?” Journal of Applied Econometrics 23: 798-824.

Barnett, W. A., and A. Serletis (2008). "Consumer Preferences and Demand Systems." Journal of Econometrics 147: 210-24.

Barnett, W. A., and A. Serletis (2009). "The Differential Approach to Demand Analysis and the Rotterdam Model.” In D. J. Slottje (ed) Quantifying Consumer Preferences. Bingley, UK: Emerald Group Publishing. Pp.61 - 81.

Barten, A. P. (1964). "Consumer Demand Functions Under Conditions of Almost Additive Preferences.” Econometrica 32: 1-38.

Barten, A. P. (1967). "Evidence on the Slutsky Conditions for Consumer Demand.” Review of Economics and Statistics 49: 77-84.

Barten, A. P. (1968). “Estimating Demand Equations.” Econometrica 36: 213-51.

Barten, A. P. (1977). “The Systems of Consumer Demand Functions Approach: A Review.” Econometrica 45: 23-51.

Barten, A. P. (1989). “Toward a Levels Version of the Rotterdam and Related Demand Systems.” In B. Cornet and H. Tulkens (eds) Contributions to Operations Research and Economics: The Twentieth Anniversary of CORE. Cambridge, Mass. : MIT Press. Pp. 441-65.

Barten, A. P. (1992). "The Estimation of Mixed Demand Systems.” In R. A. Bewley and T. V. Hoa (eds), Contributions to Consumer Demand and Econometrics: Essays in Honour of Henri Theil. Macmillan: London, UK. Pp. 31-57.

Barten A. P., and L. J. Bettendorf (1989). "Price Formation of Fish: An Application of an Inverse Demand System.” European Economic Review 33: 1509-25.

Barten A. P., and E. Geyskens (1975). “The Negativity Condition in Consumer Demand.” European Economic Review 6: 227-60.

Berner, R. (1977). “Estimating Consumer Import Demand Equations.” International Finance Discussion Paper No. 105, Board of Governors of the Federal Reserve System, Washington, DC.

Bewley, R. A. (1986). Allocation Models: Specification, Estimation and Applications. Cambridge Mass: Ballinger Publishing Co.

Bewley, R. A. (2000). "Mr Henri Theil: An Interview with the International Journal of Forecasting." International Journal of Forecasting 16: 1-16.

Blaug, M. , ed., (1999). Who's Who in Economics. Third Edition. Cheltenham, UK and Northampton, MA, USA: Edward Elgar.

Blundell, R. (1988). “Consumer Behaviour: Theory and Empirical Evidence: A Survey.” Economic Journal 98: 16-65.

Brown, A., and A. Deaton, (1972). "Surveys in Applied Economics: Models of Consumer Behaviour." Economic Journal 82: 1145-236.

Byron, R. P. (1984). “On the Flexibility of the Rotterdam Model.” European Economic Review 24: 273-84.

Capps, O., Jr., J. Church, H. A. Love (2003). "Specification Issues and Confidence Intervals in Unilateral Price Effects Analysis.” Journal of Econometrics 113: 3-31.

Chen, D. L. (1999). World Consumption Economics. Singapore: World Scientific Publishing.

Christensen, L. R., D. W. Jorgenson and L. J. Lau (1975). "Transcendental Logarithmic Utility Functions.” American Economic Review 65: 367-83. 
Clements, K. W. (2001). "Henri Theil, 1924 - 2000.” International Journal of Forecasting 17: 141-42.

Clements, K. W. (2008). "Price Elasticities of Demand are Minus One-Half.” Economics Letters 99: 490-93.

Clements, K. W. and G. Gao (2014). "The Rotterdam Demand Model. Half a Century On.” Forthcoming Economics Discussion Paper 14.34. The University of Western Australia.

Clements, K. W., and P. Nguyen (1980). "Money Demand, Consumer Demand and Relative Prices in Australia.” Economic Record 56: 338-46.

Clements, K. W., and E. A. Selvanathan (1988). "The Rotterdam Demand Model and its Application in Marketing.” Marketing Science 7: 60-75.

Clements, K. W., and S. Selvanathan (1991). "The Economic Determinants of Alcohol Consumption." Australian Journal of Agricultural Economics 35: 209-31.

Clements, K. W., and S. Selvanathan (1994). “Understanding Consumption Patterns.” Empirical Economics 19: 69-110.

Clements, K. W., and H. Theil (1979). “A Cross-Country Analysis of Consumption Patterns.” Report 7924 of the Center for Mathematical Studies in Business and Economics, The University of Chicago. Subsequently published in H. Theil Studies in Global Econometrics. Dordrecht: Kluwer Academic Publishers, 1996, pp. 95-108.

Clements, K. W., and X. Zhao (2009). Economics and Marijuana: Consumption, Pricing and Legalisation. Cambridge: Cambridge University Press.

Cranfield, J. A. L. and S. Pellow (2004). "The Role of Global vs. Local Negativity in Functional Form Selection: An Application to Canadian Consumer Demands.” Economic Modelling 21: 345-60.

Cranfield, J. A. L., P. V. Preckel, J. S. Eales and T. W. Hertel (2004). "Simultaneous Estimation of an Implicit Directly Additive Demand System and the Distribution of Expenditure-An Application of Maximum Entropy.” Economic Modelling 2: 361-85.

Deaton, A. S. (1974). "A Reconsideration of the Empirical Implications of Additive Preferences.” Economic Journal 84: 338-48.

Deaton, A. S. (1986). “Demand Analysis.” In Z. Griliches and M. D. Intriligator (eds) Handbook of Econometrics. Volume III. Amsterdam: North-Holland Publishing Company. Pp. 1768-839.

Deaton, A. S., and J. Muellbauer (1980a). “An Almost Ideal Demand System.” American Economic Review 70: 312-26.

Deaton, A. S. and J. Muellbauer (1980b). Economics and Consumer Behaviour. Cambridge: Cambridge University Press.

Deaton, A. S., and C. Paxson (1998). "Economies of Scale, Household Size, and the Demand for Food." Journal of Political Economy 106: 897-930.

Divisia, F. (1925). "L’indice Monetaire et la theorie de la monnaie.” Revue d'Economie Politique 39: 9801008.

Duffy, M. H. (1987). "Advertising and the Inter-Product Distribution of Demand: A Rotterdam Model Approach.” European Economic Review 31: 1051-70.

Duffy, M. (2002). "On the Estimation of an Advertising-Augmented, Cointegrating Demand System." Economic Modelling 20: 181-206.

Fayyad, S. K. (1986). "A Microeconomic System-Wide Approach to the Estimation of the Demand for Money.” Federal Reserve Bank of St Louis Review August-September: 22-33.

Fiebig, D. G., J. L. Seale, Jr., and H. Theil (1987). "The Demand for Energy: Evidence from a Cross-Country Demand System.” Energy Economics 9: 149-53.

Filippini, M., G. Masiero and K. Moschetti (2009). "Regional Consumption of Antibiotics: A Demand System Approach.” Economic Modelling 26: 1389-97.

Friedman, M. (1962). Price Theory: A Provisional Text. Chicago: Aldine.

Frisch, R. (1932). New Methods of Measuring Marginal Utility. Tubingen: J. C. B. Mohr.

Frisch, R. (1959). "A Complete Scheme for Computing All Direct and Cross Demand Elasticities in a Model with Many Sectors.” Econometrica 27: 177-96.

Gao, G. (2012). “World Food Demand.” American Journal of Agricultural Economics 94: 25-51.

Goldberger, A. S. (1987). Functional Form and Utility: A Review of Consumer Demand Theory. Boulder and London: Westview Press.

Goldberger, A. S. and T. Gamaletsos (1970). "A Cross-Country Comparison of Consumer Expenditure Patterns.” European Economic Review l: 357-400.

Gorman, W. M. (1959). “Separability Utility and Aggregation.” Econometrica 27: 469-81. 
Gorman, W. M. (1968). “Conditions for Additive Separability.” Econometrica 36: 605-609.

Horowitz, I. (1978). "Review of Henri Theil, Theory and Measurement of Consumer Demand.” Interfaces 8: 109-11.

Houthakker, H. S. (1957). “An International Comparison of Household Expenditure Patterns, Commemorating the Centenary of Engel's Law.” Econometrica 25: 532-51.

Houthakker, H. S. (1960). “Additive Preferences.” Econometrica 28: 244-57.

Houthakker, H. S. (1965), “New Evidence on Demand Elasticities.” Econometrica 33: 277-88.

Hymans, S. H., and H. T. Shapiro (1976). "The Allocation of Household Income to Food Consumption." Journal of Econometrics 4: 167-88.

Keifer, N. M. (1977). “A Bayesian Analysis of Commodity Demand and Labour Supply.” International Economic Review 18: 209-18.

Keller, W. J., and J. van Driel, J. (1985). “Differential Consumer Demand Systems.” European Economic Review 27: 375-90.

Kleok, T. (2001). “Obituary: Henri Thiel, 1924-2000.” Statistica Neerlandica 55: 263-69.

Klevmarken, N. A. (1979). “A Comparative Study of Complete Systems of Demand Equations.” Journal of Econometrics 10: 165-90.

Koerts, J. (1992). “Professor Theil's Contributions to Economics.” In B. Raj and J. Koerts (eds) Henri Theil’s Contributions to Economics and Econometrics. Dordrecht, Boston, London: Kluwer Academic Publishers. Volume 1, pp. 17-24.

Kravis, I. B., A. W. Heston and R. Summers (1982). World Product and Income: International Comparisons of Real Gross Product. Baltimore Md: The John Hopkins University Press.

Laitinen, K. (1978). “Why is Demand Homogeneity So Often Rejected?” Economics Letters 1: 187-9.

Leser, C. E. V. (1960). "Demand Functions for Nine Commodity Groups in Australia.” Australian Journal of Statistics 2: 102-12.

Leser, C. E. V. (1963). “Forms of Engel Functions.” Econometrica 31: 694-703.

Li, L., Z. Song and C. Ma (2015). "Engel Curves and Price Elasticity in Urban Chinese Households." Economic Modelling 44: 236-42.

Lluch, C. and A. A. Powell (1975). "International Comparisons of Expenditure Patterns.” European Economic Review 6: 375-303.

Lluch, C., A. A. Powell and R. A. Williams (1977). Patterns in Household Demand and Saving. Oxford: Oxford University Press.

Lyons, S., K. Mayor and R. S. J. Tol (2009). "Convergence of Consumption Patterns during Macroeconomic Transition: A Model of Demand in Ireland and the OECD.” Economic Modelling 26: 702-14.

Marquez, J. (1994). "The Econometrics of Elasticities or the Elasticity of Econometrics: An Empirical Analysis of the Behavior of US Imports.” Review of Economics and Statistics 76: 471-81.

Meade, B., A. Regmi, J. L. Seale, Jr., and A. Muhammad (2014). "New International Evidence on Food Consumption Patterns: A Focus on Cross-Price Effects Based on 2005 International Comparisons." Technical Bulletin 1937. Economic Research Service, United States Department of Agriculture.

McFadden, D. (1964) “Existence Conditions for Theil-Type Preferences.” Unpublished paper, Department of Economics, University of California, Berkeley.

Meisner, J. F. (1979). "The Sad Fate of the Asymptotic Slutsky Symmetry Test for Large Systems." Economics Letters 2: 231-33.

Moschini, G., and A. Vissa (1993). "Flexible Specification of Mixed Demand Systems.” American Journal of Agricultural Economics 75: 1-9.

Mountain, D. C. (1988). “The Rotterdam model: An Approximation in Variable Space.” Econometrica 56: 477-84.

Muellbauer, J. (1978). "Review of Theory and Measurement of Consumer Demand by Henri Theil." Economic Journal 88: 161-63.

Muhammad, A., J. L. Seale, Jr., B. Meade, A. Regmi (2011). "International Evidence on Food Consumption Patterns: An Update Using 2005 International Comparison Program Data.” Technical Bulletin 1929. Economic Research Service, United States Department of Agriculture. Revised 2013.

Neves, P. D. (1987). Analysis of Consumer Demand in Portugal, 1958-1981. Memoire de Mattrise en Sciences Economiques, Universite Catholique de Louvain, Louvain-la-Neuve, Belgium.

Offenbacher, E. K. (1980). "The Basic Functions of Money: An Application of the Input Independence Transformation. “ Economics Letters 5: 353-57. 
Parks, R. W. (1969). "Systems of Demand Equations: An Empirical Comparison of Alternative Functional Forms.” Econometrica 37: 629-50.

Parks, R. W., and A. P. Barten (1973). "A Cross-Country Comparison of the Effects of Prices, Income and Population Composition on Consumption Patterns.” Economic Journal 83: 834-52.

Phlips, L. (1974). Applied Consumption Analysis. Amsterdam: North-Holland Publishing Company. Second edition 1983.

Pigou, A. C. (1910). “A Method of Determining the Numerical Value of Demand Elasticities.” Economic Journal 20: 636-40.

Pollak, R. A., and T. J. Wales (1987). "Pooling International Consumption Data.” Review of Economics and Statistics 69: 90-99.

Pollak, R. A., and T. J. Wales (1992). Demand System Specification and Estimation. New York and Oxford: Oxford University Press.

Powell, A. A. (1974). Empirical Analytics of Demand Systems. Lexington Mass: DC Heath and Company.

Powell, A. A. (1992). "Sato's Insight on the Relation Between the Frisch 'Parameter' and the Average Elasticity of Substitution". Economics Letters 40: 173-75.

Raj, B. (1992). "Henri Theil's Biography and his Contributions to Economics and Econometrics: An Overview.” In B. Raj and J. Koerts (eds) Henri Theil’s Contributions to Economics and Econometrics. Dordrecht, Boston, London: Kluwer Academic Publishers. Volume 1, pp. 3-16.

Regmi, A., and J. L. Seale, Jr. (2010). “Cross-Price Elasticities of Demand Across 114 Countries.” Technical Bulletin No. 1925, Economic Research Service, United States Department of Agriculture.

Rimmer, M. T., and A. A. Powell (1992). "Demand Patterns Across the Development Spectrum: Estimates for the AIDADS System.” Preliminary Working Paper No. OP-75, Centre of Policy Studies and Impact Project, Monash University.

Seale, J. L., Jr, and C. B. Moss, eds, (2003). "Henri (Hans) Theil Memorial.” Journal of Agricultural and Applied Economics 55, supplementary issue.

Seale, J. L., Jr., A. Regmi (2006). "Modelling International Consumption Patterns.” Review of. Income and Wealth 52: 603-24.

Seale, J. L., Jr., A. Regmi (2009). "International Consumption Patterns: Evidence from the 1996 International Comparison Programme.” In S. Ghatak and P. Levine (eds), Development Macroeconomics: Essays in Memory of Anita Ghatak. Routledge, Taylor and Francis Group: London and New York. Pp. 25299.

Seale, J. L., Jr., A. Regmi and A., J. Bernstein (2003). "International Evidence on Food Consumption Patterns.” Technical Bulletin 1904. Economic Research Service, United States Department of Agriculture, Washington, D.C.

Seale, J. L., Jr., and A. A. Solano (2012). "The Changing Demand for Energy in Rich and Poor Countries over 25 Years.” Energy Economics 34: 1834-44.

Seale, J. L., Jr., A. L. Sparks and B. M. Buxton (1992). "A Rotterdam Application to International Trade in Fresh Apples: A Differential Approach.” Journal of Agricultural and Resource Economics 17: 138-49.

Seale, J. L., Jr., W. E. Walker and I-M. Kim (1991). "The Demand for Energy: Cross-Country Evidence Using the Florida Model.” Energy Economics 13: 33-40.

Selvanathan, E. A. (1989). “Advertising and Consumer Demand: A Differential Approach.” Economics Letters 31: 215-19.

Selvanathan, E. A. (1991). “Further Results on Aggregation of Differential Demand Equations.” Review of Economic Studies 58: 799-805.

Selvanathan, E. A. (1995a). “Advertising and Consumption: A Theoretical Analysis.” Chapter 7 in E. A. Selvanathan and K. W. Clements (eds) Recent Developments in Applied Demand Analysis: Alcohol, Advertising and Global Consumption. Berlin/Heidelberg: Springer-Verlag. Pp. 259-95.

Selvanathan, E. A. (1995b). "The Effects of Advertising on Alcohol Consumption: An Empirical Analysis." Chapter 8 in E. A. Selvanathan and K. W. Clements (eds) Recent Developments in Applied Demand Analysis: Alcohol, Advertising and Global Consumption. Berlin/Heidelberg: Springer-Verlag. Pp. 297-340.

Selvanathan, E. A. (1995c). "The Rotterdam Model in Forecasting: An Application to the Alcohol Market." Chapter 9 in E. A. Selvanathan and K. W. Clements (eds) Recent Developments in Applied Demand Analysis: Alcohol, Advertising and Global Consumption. Berlin/Heidelberg: Springer-Verlag. Pp. 341-58. 
Selvanathan, E. A. and S. Selvanathan (2003). International Consumption Comparisons: OECD versus LDC. Singapore: World Scientific.

Selvanathan, S. (1991). "Regional Consumption Patterns in Australia: A System- Wide Analysis.” Economic Record 67: 338-45.

Selvanathan, S. (1993). A System-Wide Analysis of International Consumption Patterns. Boston, Dordrecht and London: Kluwer Academic Publishers.

Selvanathan, S., and E. A. Selvanathan (1994). Regional Consumption Patterns: A System-Wide Approach. London: Avebury Publishers.

Stigler, G. J., and G. S. Becker (1977). "De Gustibus Non Est Disputandum.” American Economic Review 67: 79-90.

Stone, R. (1954). "Linear Expenditure Systems and Demand Analysis: An Application to the Pattern of British Demand.” Economic Journal 64: 511-27.

Theil, H. (1965). “The Information Approach to Demand Analysis.” Econometrica 33: 67-87.

Theil, H. (1967). Economics and Information Theory. New York: Elsevier/North-Holland, Inc. and Amsterdam: North-Holland Publishing Company.

Theil, H. (1971). Principles of Econometrics. New York: John Wiley and Sons.

Theil, H. (1975/76). Theory and Measurement of Consumer Demand. Two Volumes. Amsterdam: NorthHolland Publishing Company.

Theil, H. (1980). The System-Wide Approach to Microeconomics. Chicago: The University of Chicago Press.

Theil, H. (1987). "Evidence from International Consumption Comparisons." Chapter 2 in H. Theil and K. W. Clements, Applied Demand Analysis: Results from System-Wide Approaches. Cambridge, Mass. : Ballinger. Pp. 37-100.

Theil, H. (1996). Studies in Global Econometrics. Dordrecht, Holland: Kluwer Academic Publishers.

Theil, H., C-F. Chung and J. L. Seale, Jr (1989). International Evidence on Consumption Patterns. Greenwich, Connecticut: JAI Press, Inc.

Theil, H., and K. W. Clements (1978). "A Simple Method of Estimating Price Elasticities in International Trade" (with H. Theil). Economics Letters 1: 133-37.

Theil, H., and K. W. Clements (1987). Applied Demand Analysis: Results from System-Wide Approaches. Cambridge Mass: Ballinger Publishing Co.

Theil, H., and F. E. Suhm (1981). International Consumption Comparisons: A System-Wide Approach. Amsterdam: North- Holland Publishing Company.

Timmer, C. P., and H. Alderman (1979). "Estimating Consumption Parameters for Food Policy Analysis." American Journal of Agricultural Economics 61: 982-87.

Tridimas, G. (2000). "The Analysis of Consumer Demand in Greece: Model Selection and Dynamic Specification.” Economic Modelling 17: 455-71

Vilcassim, N. J. (1989). "Extending the Rotterdam Model to Test Hierarchical Market Structures.” Marketing Science 8: 181-90.

Working, H. (1943). "Statistical Laws of Family Expenditure." Journal of the American Statistical Association 38: 43-56.

Yu, W., T. W. Hertel, P. V. Preckel and J. S. Eales (2003). "Projecting World Food Demand Using Alternative Demand Systems.” Economic Modelling 21: 99-129.

Zhao, X. (2008). "Review of S. Selvanathan and E. A. Selvanathan, The Demand for Alcohol, Tobacco and Marijuana: International Evidence.” Economic Record 84: 520-22. 
FIGURE 1

\section{CITATIONS OF FOUR DEMAND MODELS}

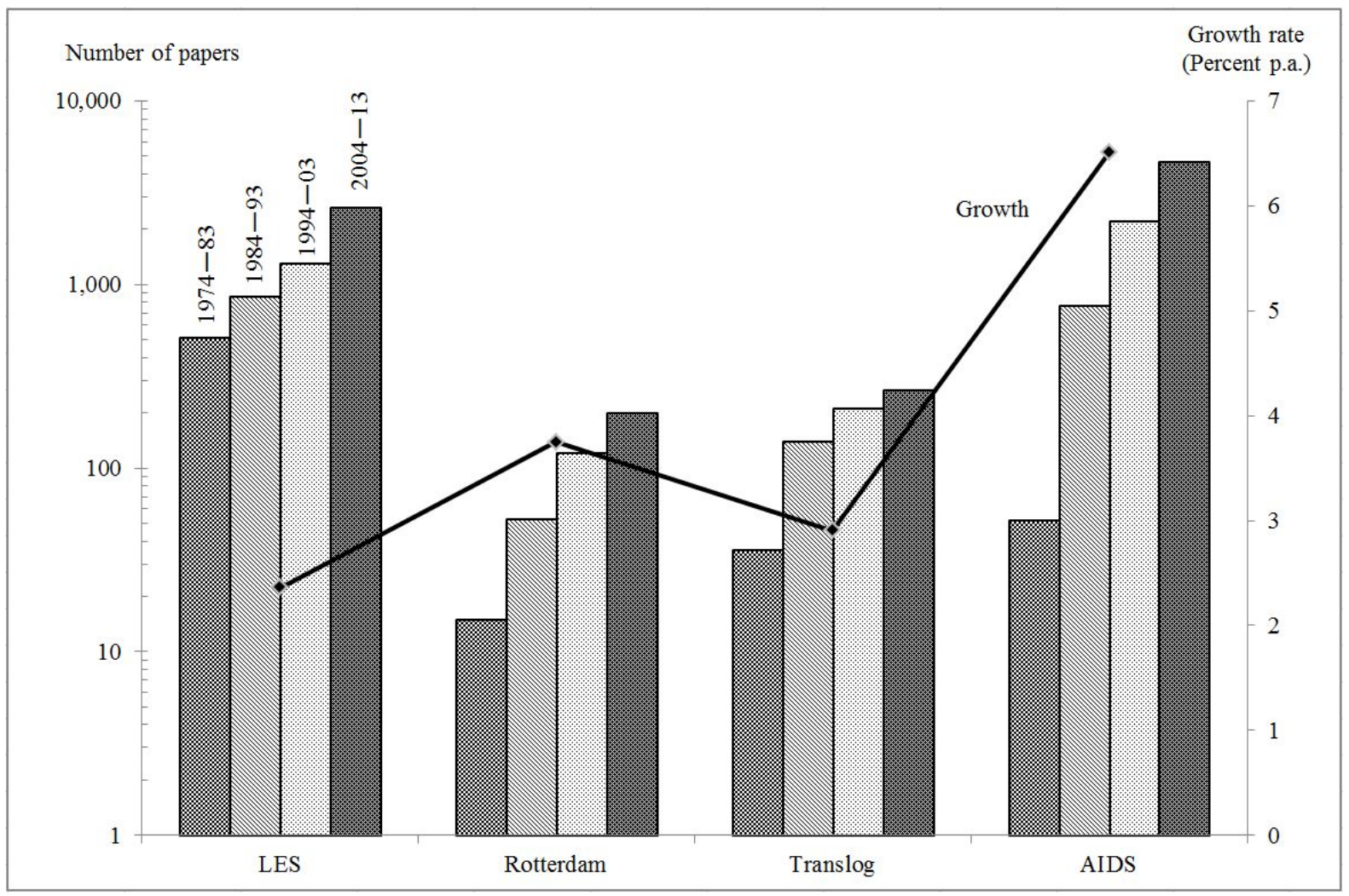

Note: This figure gives the results of keyword searches conducted in September 2014 using Google Scholar (http://scholar.google.com.au). Search terms are "linear expenditure system”, "Rotterdam demand”, "translog demand", and "almost ideal demand" for the categories on the horizontal axis. Duplicate articles were removed. The height of each column represents the number of citations, measured against the left-hand axis (labelled "Number of papers" as the vast majority of citations are by papers). The right-hand axis gives the annual growth rate in citations, calculated as 100 times the logarithm of the ratio of the number of citations in the period 2004-13 to that in 1974-83, divided by 30 (the number of years between the first and last periods). 


\section{TABLE 1}

DIFFERENTIAL REPRESENTATION OF SIX DEMAND SYSTEMS

$$
\begin{gathered}
\mathrm{w}_{\mathrm{i}} \mathrm{d}\left(\log \mathrm{q}_{\mathrm{i}}\right)=\theta_{\mathrm{i}} \mathrm{d}(\log \mathrm{Q})+\sum_{\mathrm{j}=1}^{\mathrm{n}} \mathrm{v}_{\mathrm{ij}}\left[\mathrm{d}\left(\log \mathrm{P}_{\mathrm{j}}\right)-\mathrm{d}\left(\log \mathrm{P}^{\prime}\right)\right], \quad \mathrm{i}=1, \ldots, \mathrm{n} \\
\mathrm{w}_{\mathrm{i}} \mathrm{d}\left(\log \mathrm{q}_{\mathrm{i}}\right)=\theta_{\mathrm{i}} \mathrm{d}(\log \mathrm{Q})+\sum_{\mathrm{j}=1}^{\mathrm{n}} \pi_{\mathrm{ij}} \mathrm{d}\left(\log \mathrm{P}_{\mathrm{j}}\right), \quad \mathrm{i}=1, \ldots, \mathrm{n}
\end{gathered}
$$

Function to be
optimised

(1)

$-$

$\mathrm{w}_{\mathrm{i}}=\alpha_{\mathrm{i}}+\beta_{\mathrm{i}} \log \mathrm{M}$

Marginal
share
$\theta_{i}$

(3)

Income
flexibility

$\phi$

Price
coefficient

$v_{\mathrm{ij}}$

(5)
Slutsky coefficient

$\pi_{\mathrm{ij}}$

(6)

\section{A. Working's Model}

$\mathrm{w}_{\mathrm{i}}+\beta_{\mathrm{i}}$

\begin{tabular}{|c|c|c|c|c|c|}
\hline $\begin{array}{l}\text { Direct utility } \\
\sum_{\mathrm{i}=1}^{\mathrm{n}} \beta_{\mathrm{i}} \log \left(\mathrm{q}_{\mathrm{i}}-\gamma_{\mathrm{i}}\right)\end{array}$ & $\begin{array}{c}\mathrm{w}_{\mathrm{i}}=\frac{\mathrm{p}_{\mathrm{i}} \gamma_{\mathrm{i}}}{\mathrm{M}}+\beta_{\mathrm{i}}\left(\frac{\mathrm{M}-\mathbf{p}^{\prime} \boldsymbol{\gamma}}{\mathrm{M}}\right), \\
\mathbf{p}^{\prime} \boldsymbol{\gamma}=\sum_{\mathrm{j}=1}^{\mathrm{n}} \mathrm{p}_{\mathrm{j}} \gamma_{\mathrm{j}}\end{array}$ & $\beta_{\mathrm{i}}=$ constant & $\frac{\mathbf{p}^{\prime} \gamma-M}{M}$ & $\begin{array}{l}\left(\frac{\mathbf{p}^{\prime} \gamma-\mathrm{M}}{\mathrm{M}}\right) \beta_{\mathrm{i}} \delta_{\mathrm{ij}}, \\
\delta_{\mathrm{ij}}=1 \text { if } \mathrm{i}=\mathrm{j}, 0 \text { otherwise }\end{array}$ & $\left(\frac{M-\mathbf{p}^{\prime} \boldsymbol{\gamma}}{M}\right) \beta_{\mathrm{i}}\left(\beta_{\mathrm{j}}-\delta_{\mathrm{ij}}\right)$ \\
\hline $\begin{array}{l}\text { Direct utility } \\
\sum_{\mathrm{i}=1}^{\mathrm{n}} \mathrm{a}_{\mathrm{i}} \mathrm{q}_{\mathrm{i}}+\frac{1}{2} \sum_{\mathrm{i}=1}^{\mathrm{n}} \sum_{\mathrm{j}=1}^{\mathrm{n}} \mathrm{u}_{\mathrm{ij}} \mathrm{q}_{\mathrm{i}} \mathrm{q}_{\mathrm{j}} \\
=\mathbf{a}^{\prime} \mathbf{q}+\frac{1}{2} \mathbf{q}^{\prime} \mathbf{U} \mathbf{q}\end{array}$ & $\begin{array}{l}\mathrm{w}_{\mathrm{i}}=\frac{\mathrm{P}_{\mathrm{i}}}{\mathrm{M}} \sum_{\mathrm{j}=1}^{\mathrm{n}} \mathrm{u}^{\mathrm{ij}}\left(\mathrm{a}_{\mathrm{j}}+\lambda \mathrm{P}_{\mathrm{j}}\right) \\
\mathrm{u}^{\mathrm{ij}}=(\mathrm{i}, \mathrm{j})^{\mathrm{th}} \text { element of } \mathbf{U}^{-1} \\
\lambda=\text { marginal utility of income }\end{array}$ & $\begin{array}{l}\frac{1}{\mathbf{p}^{\prime} \mathrm{U}^{-1} \mathbf{p}} \sum_{\mathrm{j}=1}^{\mathrm{n}} \mathrm{u}^{\mathrm{ij}} \mathrm{p}_{\mathrm{i}} \mathrm{p}_{\mathrm{j}} \\
\mathbf{p}=\left[\mathrm{p}_{\mathrm{i}}\right]\end{array}$ & $\frac{\mathbf{p}^{\prime} \mathbf{U}^{-1} \mathbf{a}+\mathbf{M}}{\mathrm{M}}$ & $\frac{\lambda}{\mathrm{M}} \mathrm{u}^{\mathrm{ij}} \mathrm{p}_{\mathrm{i}} \mathrm{p}_{\mathrm{j}}$ & $\frac{\lambda \mathrm{p}_{\mathrm{i}} \mathrm{p}_{\mathrm{j}}}{\mathrm{M}}\left(\mathrm{u}^{\mathrm{ij}}-\frac{\mathbf{p}^{\prime} \mathbf{U}^{-1} \mathbf{U}^{-1} \mathbf{p}}{\mathbf{p}^{\prime} \mathbf{U}^{-1} \mathbf{p}}\right)$ \\
\hline
\end{tabular}

B. Linear Expenditure System 
TABLE 1 (Continued)

DIFFERENTIAL REPRESENTATION OF SIX DEMAND SYSTEMS

$$
\begin{gathered}
\mathrm{w}_{\mathrm{i}} \mathrm{d}\left(\log \mathrm{q}_{\mathrm{i}}\right)=\theta_{\mathrm{i}} \mathrm{d}(\log \mathrm{Q})+\sum_{\mathrm{j}=1}^{\mathrm{n}} \mathrm{v}_{\mathrm{ij}}\left[\mathrm{d}\left(\log \mathrm{P}_{\mathrm{j}}\right)-\mathrm{d}\left(\log \mathrm{P}^{\prime}\right)\right], \quad \mathrm{i}=1, \ldots, \mathrm{n} \\
\mathrm{w}_{\mathrm{i}} \mathrm{d}\left(\log \mathrm{q}_{\mathrm{i}}\right)=\theta_{\mathrm{i}} \mathrm{d}(\log \mathrm{Q})+\sum_{\mathrm{j}=1}^{\mathrm{n}} \pi_{\mathrm{ij}} \mathrm{d}\left(\log \mathrm{P}_{\mathrm{j}}\right), \quad \mathrm{i}=1, \ldots, \mathrm{n}
\end{gathered}
$$

Function to be
optimised

(1)

\section{Budget share \\ equation}

(2)

Income
flexibility

$\phi$

Price
coefficient

$\theta_{\mathrm{i}}$

(3)
(4)
Slutsky coefficient

$\pi_{\mathrm{ij}}$

(6)

Indirect utility

\section{Translog}

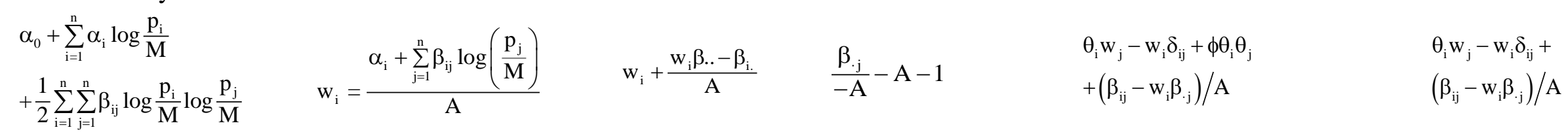

\section{E. Almost Ideal Demand System}

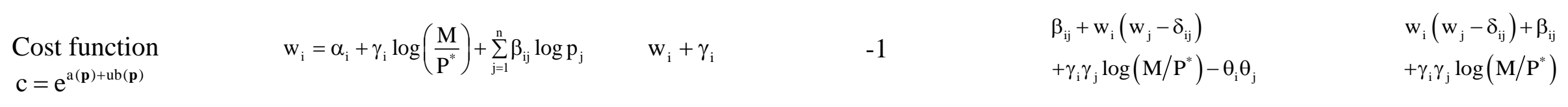

\begin{tabular}{|c|c|c|}
\hline $\begin{array}{l}\text { Direct utility } \\
\mathrm{u}(\mathbf{q})\end{array}$ & $\overline{\mathrm{w}}_{\mathrm{i}} \mathrm{Dq}_{\mathrm{it}}=\theta_{\mathrm{i}} \mathrm{DQ}_{\mathrm{t}}+\sum_{\mathrm{j}=1}^{\mathrm{n}} \pi_{\mathrm{ij}} \mathrm{Dp}_{\mathrm{jt}}$ & $\theta_{\mathrm{i}}=$ constant \\
\hline
\end{tabular}

\section{F. Rotterdam Model}

Note: In panel $D, A=\sum_{i=1}^{n}\left[\alpha_{i}+\sum_{j=1}^{n} \beta_{i j} \log \left(p_{j} / M\right)\right], \beta_{i}=\sum_{j=1}^{n} \beta_{i j}=\sum_{i=1}^{n} \beta_{i j}=\beta_{. j}$ and $\beta=\sum_{i=1}^{n} \beta_{i}$. In panel $E, a(p)=\sum_{i=1}^{n} \alpha_{i} \log p_{i}+(1 / 2) \sum_{i=1}^{n} \sum_{j=1}^{n} \beta_{i j}^{*} \log p_{i} \cdot \log p_{j}, b(\mathbf{p})=\gamma_{0} \Pi_{i=1}^{n} p_{i}^{\gamma_{i}}$ and $\log \mathrm{P}^{*}=\sum_{\mathrm{i}=1}^{\mathrm{n}} \alpha_{\mathrm{i}} \log \mathrm{p}_{\mathrm{i}}+(1 / 2) \sum_{\mathrm{i}=1}^{\mathrm{n}} \sum_{\mathrm{j}=1}^{\mathrm{n}} \beta_{\mathrm{ij}} \log \mathrm{p}_{\mathrm{i}} \cdot \log \mathrm{p}_{\mathrm{j}}$, with $\beta_{\mathrm{ij}}=\left(\beta_{\mathrm{ij}}^{*}+\beta_{\mathrm{ji}}^{*}\right) / 2$. 
TABLE 2

MILESTONES IN DEVELOPMENT OF THE ROTTERDAM AND RELATED MODELS OF CONSUMER DEMAND

\begin{tabular}{|c|c|}
\hline Topic & Reference \\
\hline \multirow{3}{*}{ Initial formulation } & Barten (1964) “Consumer Demand Functions” \\
\hline & Theil (1965) “Information Approach” \\
\hline & Theil (1967) Economics and Information Theory \\
\hline \multirow{3}{*}{ Estimation and testing } & Barten (1967) “Evidence on Slutsky” \\
\hline & Barten (1968) “Estimating Demand Equations” \\
\hline & Barten and Geyskens (1975) “Negativity Condition” \\
\hline $\begin{array}{l}\text { Comprehensive presentation and } \\
\text { extensions }\end{array}$ & Theil (1975/76) Theory and Measurement of Consumer Demand \\
\hline \multirow{2}{*}{ More testing } & Laitinen (1978) “Demand Homogeneity” \\
\hline & Meisner (1979) “Slutsky Symmetry” \\
\hline Cobb-Douglas Utility? & McFadden (1964) “Existence of Theil-Type Preferences” \\
\hline \multirow{3}{*}{ Aggregation over consumers } & Theil (1971) Principles of Econometrics \\
\hline & Barnett (1979b) “Theoretical Foundations of Rotterdam Model” \\
\hline & $\begin{array}{l}\text { E. A. Selvanathan (1991) “Aggregation of Differential Demand } \\
\text { Equations” }\end{array}$ \\
\hline \multirow[t]{2}{*}{ Introduction of labour supply } & Barnett (1981) Consumer Demand and Labour Supply \\
\hline & Byron (1984) “Flexibility of Rotterdam” \\
\hline \multirow[t]{2}{*}{ Approximation properties } & Barnett (1984) “Flexibility of Rotterdam” \\
\hline & Mountain (1988) “Approximation in Variable Space” \\
\hline Inverse Rotterdam model & Barten and Bettendorf (1989) “Inverse Demand System” \\
\hline \multirow{5}{*}{ Cross-country consumption analysis } & Clements and Theil (1979) “Cross-country Consumption” \\
\hline & Theil and Suhm (1981) International Consumption Comparisons \\
\hline & Theil, Chung and Seale (1989) International Consumption Patterns \\
\hline & Seale, Walker and Kim (1991) “Florida Model” \\
\hline & Seale and Regmi (2006) “Modelling International Consumption” \\
\hline
\end{tabular}

Theory, econometric methodology and applications

Theil and Clements (1987) Applied Demand Analysis

Note: Items are listed in approximate chronological order and grouped by broad topic. Titles of works are abbreviated; for full details, see list of references at end. 